\title{
POLLEN MORPHOLOGY OF GENUS RUBUS L. PART III. STUDIES ON THE MALESIAN SPECIES OF SUBGENERA CHAMAEBATUS L. AND IDAEOBATUS L.
}

\author{
ANNA TOMLIK-WYREMBLEWSKA ${ }^{1}$, \\ RAYMOND W.J.M. VAN DER HAM ${ }^{2}$, PIOTR KOSIŃSKI ${ }^{3}$ \\ ${ }^{1}$ Department of Systematics and Geography of Plants, \\ Institute of Dendrology Polish Academy of Sciences \\ Parkowa 5, 62-035 Kórnik, Poland \\ e-mail: tomlik@rose.man.poznan.pl \\ 2 Nationaal Herbarium Nederland, Leiden University \\ P.O. Box 9514, 2300 RA Leiden, The Netherlands \\ ${ }^{3}$ Department of Botany, August Cieszkowski Agriculture University \\ Wojska Polskiego 71c, 60-625 Poznań, Poland
}

(Received: July 28, 2003. Accepted: May 10, 2004)

\begin{abstract}
The results of pollen morphology of Malesian Rubus species are presented. The pollen samples represented 2 subgenera; 2 species of subgenus Chamaebatus (R. calycinus, $R$. pectinellus) and 13 species of subgenus Idaeobatus ( $R$. acuminatissimus, $R$. alpestris, $R$. archboldianus, $R$. chrysogaeus, $R$. copelandii, $R$. ellipticus, $R$. ferdinandi-muelleri, $R$. fraxinifolius, $R$. niveus, $R$. lorentzianus, $R$. macgregorii, $R$. montis-wilhelmi, $R$. papuanus). The examination of these species has been made by SEM for the first time and also by LM. Detailed descriptions of the pollen grains are given. As in the majority of Rubus species, pollen grains of both subgenera are isopolar and trizonocolporate. The pollen grains were small for some species of the subgenus Idaeobatus only, medium for both subgenera: Chamaebatus and Idaeobatus. The thickest exine was observed among the species of subgenus Chamaebatus and in R. macgregorii of subgenus Idaeobatus. The ornamentation of the studied pollen has shown a great variability. Except for the typical striate ornamentation of the genus, rugulate $(R$. archboldianus), striatescabrate (R. lorentzianus) and striate-rugulate (R. macgregorii) ornamentation has been observed.

New Guinean morphologically similar pinnate Rubus ferdinandi-muelleri, $R$. montis-wilhelmi, $R$. papuanus, have pollen with specific type of striate pattern, which is characterised by relatively high muri with variable thickness and lumina filled with granules. Some of their muri resemble baculae typical only for $R$. chamaemorus. The pollen morphology analysis leads to the conclusion that Rubus montis-wilhelmi and R. papuanus of subgenus Idaeobatus are the closest related species and morphologically very close to $R$. ferdinandi-muelleri. Since Focke placed the latter species in section Pungentes of the subgenus Idaeobatus, and the two first species were unknown to him - the authors suggest to include them into this section.

Despite of the different origin and various types of leaves $R$. chrysogaeus, $R$. acuminatissimus and $R$. niveus have shown similarities in pollen morphology and are grouped together. On the basis of the same criteria, $R$. copelandii, $R$. ellipticus and $R$. fraxinifolius could have been grouped together, as well as $R$. alpestris and $R$. macgregorii. Trifoliolate $R$. archboldianus and $R$. lorentzianus have not shown similarities of pollen ornamentation to each other and to the previous mentioned species.
\end{abstract}

KEY WORDS: Rubus subgenus Chamaebatus, Idaeobatus, pollen morphology, SEM, LM.

\section{INTRODUCTION}

Continuing the review of Rubus pollen diversity among Malesian species, the subgenera Chamaebatus and Idaeobatus have been studied. The species of subgenus Chamaebatus occur in America (NW America and Mexico) and in
Asia (China, Taiwan, Japan, Philippines, and Java). Among the five species distinguished by Focke (1911) in this subgenus, two species occur in Malesia.

According to Kalkman's description (Zandee and Kalkman 1981), the small subgenus Chamaebatus comprises small creeping plants with simple, reniform to cordate lea- 
ves, rarely more deeply incised. Stipules are free, flowers bisexual, solitary terminal, rarely 2-3 on erect laterals. Fruits are loosely cohering, becoming loose from the torus, when ripe. The area of distribution is disjunct.

Subgenus Idaeobatus includes about 100 species grouped in 9 sections (Focke 1911). The great majority is in Asia, Australia and islands in the Pacific Ocean. Some species occur in Africa and Madagascar and islands in the Indian Ocean. Few species are found in Central America and only one in Europe ( $R$. idaeus). The Malesian species are mostly mountainous and are rarely found below $1000 \mathrm{~m}$. Brambles of this subgenus are shrubs, erect or climbing. Leaves are palmately 3 to 5 -foliolate, rarely simple. Stipules at the base of the petiole are persistent. Flowers occur in thyrsoid inflorescences. Fruits are cohering, becoming loose from the torus, when ripe. The species of subgenus Idaeobatus represent 4 sections distinguished in particular description of $R u$ bus pollen. The present study describes the pollen of 13 species among the 18 dealed with by Kalkman and Zandee (1981). Pollen of the other 5 species was not available.

\section{MATERIAL AND METHODS}

Pollen samples were taken from dried material, present in the Nationaal Herbarium Nederland, Leiden. The method of preparing pollen for study was presented in previous papers (Tomlik-Wyremblewska 1995, 2000). The pollen morphological descriptions and the terminology used in the present paper are in accordance with those papers (TomlikWyremblewska 1.c.) and the literature quoted therein (Erdtman 1952; Ham 1990; Hebda et al. 1988; Hebda et al. 1987; Moore et al. 1991; Punt et al. 1974; Clarke et al. 1978; Heath 1984).

\section{POLLEN DESCRIPTIONS}

\section{SUBGENUS CHAMAEBATUS}

As mentioned before, only two species occur in Malesia, usually at altitudes between 750 and $2600 \mathrm{~m}$ in different types of forest.

The general morphology of Rubus pollen has been described already by Erdtman (1952), Reitsma (1966), Eide (1981), Moore et al. (1991), and also in the paper on Rubus subgenus Rubus and Micranthobatus pollen (Tomlik-Wyremblewska 1995, 2000). The latter general description pertains also to subgenus Chamaebatus. The differences are in the ornamentation of the pollen, development of the equatorial bridge and distinctness of the pori. The following presents description of the pollen of the individual species.

\section{Rubus calycinus D. Don}

This species from Nepal and Java has medium-sized pollen grains $(\mathrm{P} \times \mathrm{E}$ : $33.6 \times 22.8 \mu \mathrm{m})$, according to the Erdtman's classification (Erdtman 1952), elliptical in meridional outline, $\mathrm{P} / \mathrm{E}$ ratio is 1.34 (Fig. 1A; Figs 5, 6) and circular to 3-lobed in equatorial outline (Fig. 1B). The 3- lobed outline is rare because the colpi are not constricted (Fig. 1A, B).

Apertures: Ectoapertures - colpi, long, ca $85 \%$ of polar axis, tapering towards the poles (Figs 1,5). The widest part of the colpus is near the porus. The width is about 4.4 $\mu \mathrm{m}$ and is the largest of the examined species, which occur in Malesia: Rubus calycinus and $R$. pectinellus. It makes the colpus membrane very well visible. Colpus membrane granulated (Fig. 1B, marked by arrow). Margins of the colpus undifferentiated.

Endoapertures - pori, distinct in some grains, usually covered by the equatorial bridge (Fig. 1A, arrow).

Exine: The total thickness of the exine is 1.7 to 1.8 $\mu \mathrm{m}$ in the centre of mesocolpia. In LM (Fig. 6) and SEM examination (Figs 3,4) indicates 3 sublayers: tectum with supratectal elements (Fig. 4A), infratectum - columellae layer (Fig. 4B) and nexine (Fig. 4C) These layers have not been measured. The perforations are present on the tectum: there are mostly microperforations (Fig. 2).

Ornamentation: Finely striate both in LM and SEM. Muri orientated in different directions on the pole and in the mesocolpium area. In the apocolpium the muri are meandering, loose by laying on the perforate tectum; whereas in the mesocolpium, muri are orientated parallelly to the equator and often meandering, resembling a finger tip pattern (Figs 1, 2). Muri are mostly low and short, with high variation in thickness. They anastomose very often (the anastomose index is 4-5 connections per $10 \mu \mathrm{m}$ length of a murus). The meandering muri separate the relatively wide grooves, where perforations in tectum are quite distinct (Figs 2,3) and the muri often merge into the tectum. Muri anastomose by flat connections, which causes the characteristic pattern (Figs 1, 2).

\section{Rubus pectinellus Maximowicz}

This species from primary and secondary forest in the Philippines has small to medium pollen grains $(\mathrm{P} \times \mathrm{E}$ : $26.1 \times 22.5 \mu \mathrm{m})$, elliptical to circular in meridional outline (P/E ratio 1.16) (Fig. 11), circular in equatorial outline (Fig. 7).

Apertures: Ectoapertures - colpi long, approximately $85 \%$ of polar axis, wide, not constricted, the equatorial bridge not closed, showing the porus very often. Colpus membrane well visible and granulated (Fig. 7).

Endoapertures - pori distinct, sometimes covered by the undifferentiated edges of the colpi.

Exine: The total thickness of the exine in the centres of mesocolpia is $1.9 \mu \mathrm{m}$. In LM examination 3 sublayers are distinct (Figs 11, 12). The exine sublayers have not been observed with SEM, but the perforate tectum is quite well distinct (Fig. 8).

Ornamentation: Striate both in LM and SEM examination (Figs 7-10). Muri running in different directions: parallelly in apocolpium and along the colpi; curving and meandering in the mesocolpia area (Figs 7,8). Muri are compactly arranged, with narrow grooves in-between. They are short, equal in width and height, anastomosing often; the anastomose index is approximately 6-7 connections per 10 $\mu \mathrm{m}$ of a murus, the thickenings at the place of anastomoses are present. Density of the perforations is high and they are distinct in the tectum (Fig. 8). 

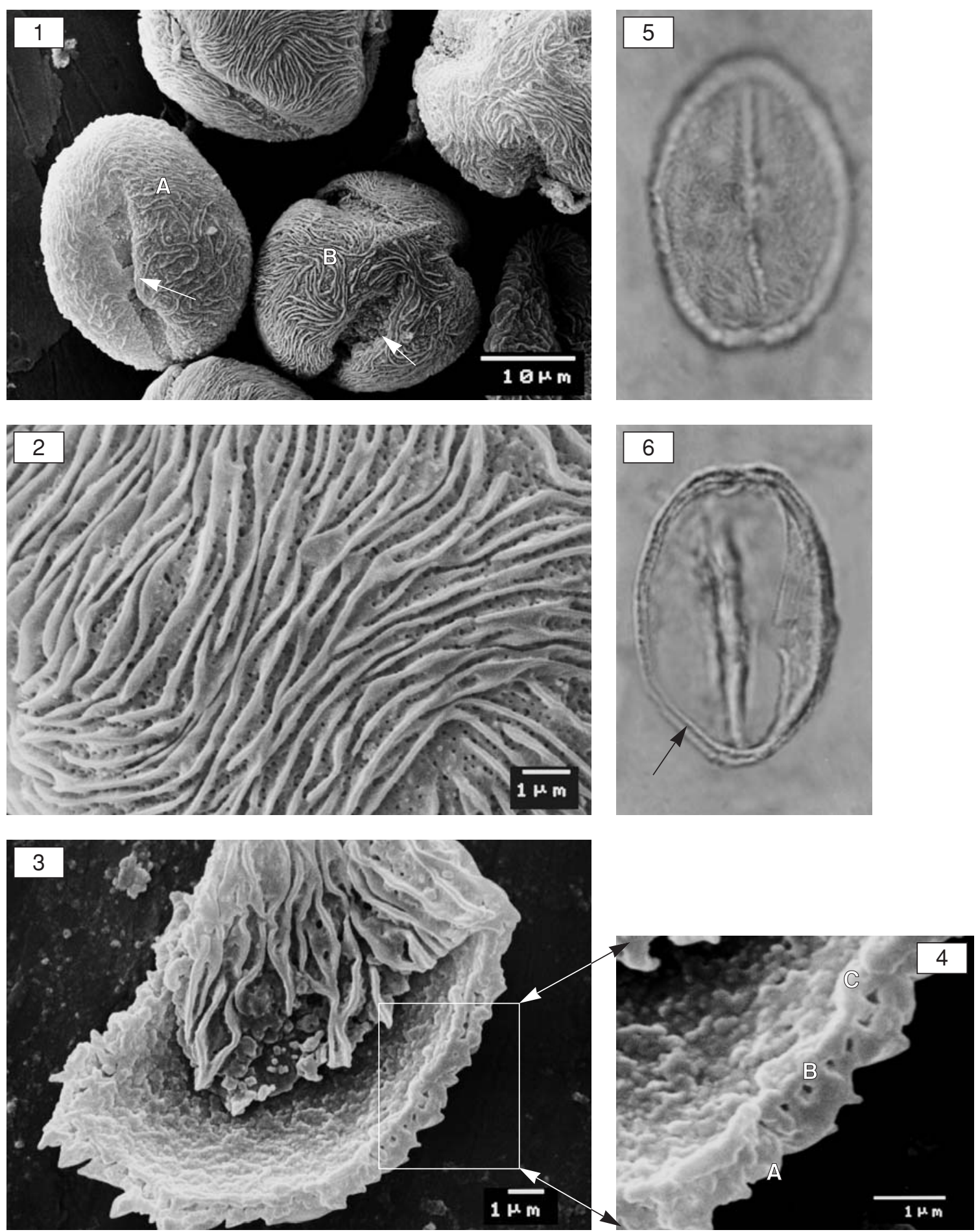

The bar in the photo (SEM) refers to magnification of the plate

Figs 1-6. Rubus calycinus pollen.

Fig. 1. (SEM). Pollen grains arranged in different direction; the equatorial view (A) and polar view (B) distinct; not constricted colpi, finely striate ornamentation, colpus membrana (arrow) and equatorial bridges distinct (arrow).

Fig. 2. (SEM). Details of striate ornamentation and muri features.

Fig. 3. (SEM). Cross-section of the exine in mesocolpium area. Magnification of the fragment marked.

Fig. 4. (SEM). Cross-section of the exine in mesocolpium area. The 3 sublayers distinct: A - tectum and supratectal elements, B - infratectum: collumelate layer, $\mathrm{C}$ - nexine.

Fig. 5. (LM). Equatorial view, striate ornamentation on mesocolpium distinct $(\times 1000)$.

Fig. 6. (LM). Equatorial view with stratification of the exine distinct $(\times 1000)$

Remarks: The pollen grains of the two representatives of subgenus Chamaebatus have two different patterns of ornamentation, not common with the species of already examined subgenera (Tomlik-Wyremblewska 1995, 2000).
SUBGENUS IDAEOBATUS (FOCKE) FOCKE

The general pattern of Rubus pollen (Erdtman 1952; Reitsma 1966; Punt et al. 1974; Clarke et al. 1978; Eide 1981; Heath 1984; Hebda et al. 1987, 1988; Moore et al. 1991; 

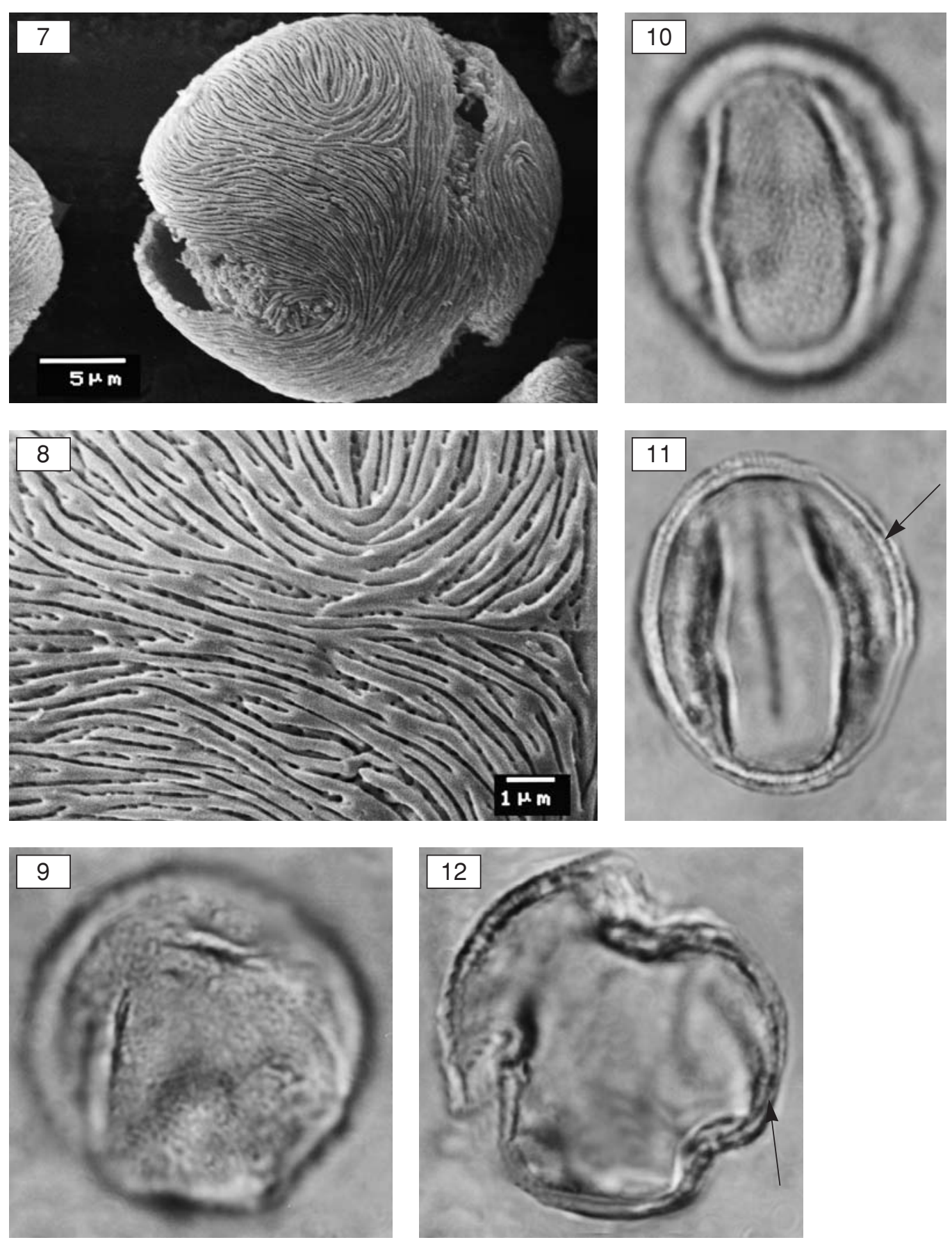

Figs 7-12. Rubus pectinellus pollen.

Fig. 7. (SEM). Oblique orientation of the pollen grain, granulate membrane separated, porus and exine distinct.

Fig. 8. (SEM). Details of striate ornamentation: narrow grows and perforation in between.

Fig. 9. (LM). Oblique orientation of the grain. Striate ornamentation on mesocolpium distinct $(\times 1000)$.

Fig. 10. (LM). Equatorial view. Striate ornamentation on mesocolpium distinct $(\times 1000)$.

Fig. 11. (LM). Equatorial view. Meridional outline with stratification of the exine distinct $(\times 1000)$.

Fig. 12. (LM). Oblique orientation of the grain. Outline with stratification distinct annd marked $(\times 1000)$.

Tomlik-Wyremblewska 1995, 2000) applies also to subgenus Idaeobatus. The particular diagnosis of the species are as follows:

Rubus acuminatissimus Hasskarl

Sect. Rosaefolii

This species occurs in a very restricted area: in Java and Sumatra only. Its pollen grains are small $(\mathrm{P} \times \mathrm{E}: 19.7 \times 14.2$ $\mu \mathrm{m})$; elliptical in meridional outline (Figs 13, 17); circular to trilobed in equatorial outline (Figs 13, 18).

Apertures: Ectoapertures - colpi long, 84.3\% length of polar axis, with acute ends, often caused by constricted edges of the colpi (Figs 13, 14 arrow, 16, 17). Colpus membrane granulated, the equatorial bridges distinct and usually constricted (closed), which makes the porus area invisi- 

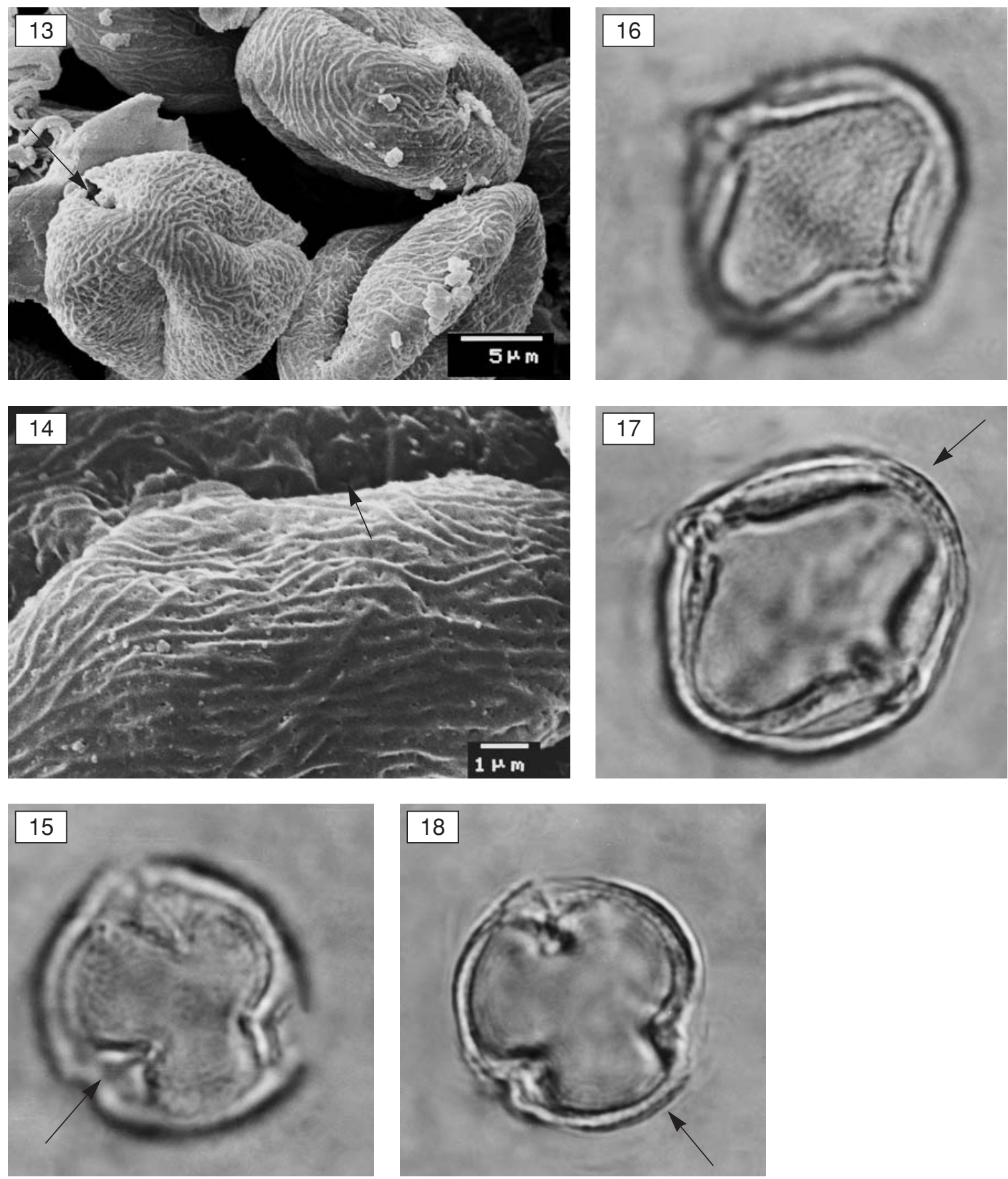

Figs 13-18. Rubus accuminatissimus pollen.

Fig. 13. (SEM). Pollen grains arranged in different directions. Polar view and equatorial view distinct.

Fig. 14. (SEM). Details of the ornamentation of the exine. Large grooves with perforations distinct.

Fig. 15. (LM). Polar view. Striate ornamentation on the polar area and apocolpium distinct, equatorial bridges not constricted, marked by arrow $(\times 1000)$. Fig. 16. (LM). Equatorial view. Striate ornamentation on the mesocolpium distinct $(\times 1000)$.

Fig. 17. (LM). Equatorial view. Meridional outline with layers of the exine partly distinct $(\times 1000)$.

Fig. 18. (LM). Polar view. Equatorial outline and stratification of the exine distinct, marked by arrow $(\times 1000)$.

ble (Figs 13, 14, 16). In Figs 13, 15, the stretched bridge is visible, occasionally showing porus (marked by arrow). Colpus margins undifferentiated.

Endoapertures - pori: rarely visible, because of equatorial bridge (Figs 13 arrow, 14, 16).

Exine: Total thickness of the exine is $1.3 \mu \mathrm{m}$ in the centres of mesocolpia (Figs 17, 18). In LM estimation 3 sublay- ers are distinct (Fig. 17), with SEM, sublayers have not been observed, but the perforate tectum is distinct (Figs 13, 14).

Ornamentation: Finely or loosely striate. Muri running perpendicularly to the colpi on mesocolpia and near the apocolpia, and meandering in the equatorial bridge surroundings. The arrangement of the muri is variable. Muri are equal in width, ca $0.18 \mu \mathrm{m}$, loosely laying on the tectum 
TABLE 1. Measurements of examined pollen grains in glycerine-jelly. The abbreviations of P, E, P/E are explained in the papers of Tomlik-Wyremblewska 1995.

\begin{tabular}{|c|c|c|c|c|c|c|c|c|}
\hline Subgenera/Species & $\begin{array}{l}\text { Length } \\
\text { of polar axis } \\
(\mathrm{P})[\mu \mathrm{m}]\end{array}$ & $\begin{array}{l}\text { Range } \\
(\mathrm{P})[\mu \mathrm{m}]\end{array}$ & $\begin{array}{l}\text { Standard } \\
\text { deviation } \\
\left(\mathrm{S}_{\mathrm{P}}\right)[\mu \mathrm{m}]\end{array}$ & $\begin{array}{l}\text { Equatorial } \\
\text { diameter } \\
\text { (E) }[\mu \mathrm{m}]\end{array}$ & $\begin{array}{l}\text { Range } \\
(\mathrm{E})[\mu \mathrm{m}]\end{array}$ & $\begin{array}{l}\text { Standard } \\
\text { deviation } \\
\left(\mathrm{S}_{\mathrm{E}}\right)[\mu \mathrm{m}]\end{array}$ & $\mathrm{P} / \mathrm{E}$ Ratio & $\begin{array}{c}\text { Exine } \\
\text { thickness } \\
{[\mu \mathrm{m}]}\end{array}$ \\
\hline \multicolumn{9}{|l|}{ Chamaebatus } \\
\hline R. calycinus & 33.56 & $28-34$ & 2.18 & 22.78 & $20-25$ & 1.78 & 1.34 & 2.01 \\
\hline R. pectinellus & 21.13 & $24-29$ & 1.55 & 22.50 & $21-25$ & 1.51 & 1.16 & 1.92 \\
\hline \multicolumn{9}{|l|}{ Idaeobatus } \\
\hline R. acuminatissimus & 19.69 & $18-21$ & 1.04 & 14.23 & $13-15$ & 0.58 & 1.38 & 1.30 \\
\hline$R$. alpestris & 30.64 & $28-33$ & 1.61 & 26.64 & $25-29$ & 1.30 & 1.15 & 1.86 \\
\hline R. archboldianus & 29.57 & $29-31$ & 0.72 & 29.50 & $28-31$ & 1.03 & 1.00 & 1.60 \\
\hline R. chrysogaeus & 17.40 & $16-18$ & 1.02 & 16.20 & $15-19$ & 1.40 & 1.07 & 1.27 \\
\hline R. copelandii & 25.00 & $24-27$ & 1.20 & 21.80 & $21-24$ & 0.97 & 1.15 & 1.55 \\
\hline R. ellipticus & 20.38 & $17-24$ & 1.59 & 15.31 & $13-17$ & 1.32 & 1.33 & 1.35 \\
\hline R. ferdinandi-muelleri & 17.27 & $16-18$ & 0.61 & 11.72 & $10-14$ & 1.05 & 1.47 & 1.23 \\
\hline$R$. fraxinifolius & 17.92 & $16-19$ & 1.28 & 14.85 & $14-17$ & 1.51 & 1.21 & 1.30 \\
\hline$R$. niveus & 24.95 & $22-26$ & 1.22 & 18.84 & $18-21$ & 0.86 & 1.30 & 1.42 \\
\hline R. lorentzianus & 34.50 & $32-38$ & 1.61 & 26.25 & $24-28$ & 1.16 & 1.31 & 1.61 \\
\hline R. macgregorii & 29.80 & $28-31$ & 0.98 & 28.90 & $25-30$ & 1.87 & 1.03 & 2.04 \\
\hline R. montis-wilhelmi & 17.23 & $16-18$ & 0.16 & 16.62 & $15-17$ & 0.93 & 1.04 & 1.31 \\
\hline R. papuanus & 17.77 & $16-19$ & 0.79 & 17.23 & $15-20$ & 1.36 & 1.03 & 1.22 \\
\hline
\end{tabular}

and anastomosing; the anastomose index is approximately 5-8 connections per $10 \mu \mathrm{m}$ length of a murus. They alternate with shallow grooves with distinct arranged perforations (Figs 13, 14).

\section{Rubus alpestris Blume}

Sect. Alpestres

This widely distributed species from Thailand, Sumatra, Borneo, Java, Celebes, Moluccas has medium-sized pollen (P×E: 30.6×26.6 um); meridional outline slightly elliptical to almost circular (Figs 19, 23), (the P/E ratio is 1.15); equatorial outline triangular. In Figs 21, 24 the oblique view is shown only, but the observation in SEM allows to observe the shape of the grains in polar view.

Apertures: Ectoapertures - colpi long, ca $80 \%$ of polar axis (Table 1), with acute ends. The margins of the colpus undifferentiated, not constricted. Colpus membrane granulated and distinct (Fig. 19, arrow B). Equatorial bridges present, not constricted. Endoapertures - lalongate pori, distinct, not covered by the equatorial bridges (Fig. 19, arrows $\mathrm{A}$ ).

Exine: The mean total thickness of the exine is about 1.9 $\mu \mathrm{m}$ in the centres of the mesocolpia and the apocolpia. In LM examination 3 sublayers are visible (Fig. 23). SEM photographs have not been taken, but many perforations in the tectum are distinct (Figs 19, 20).

Ornamentation: Striate with muri arranged in a meandering pattern. The muri surround the porus area, and curve, meander in the mesocolpium, which somehow resembles the "finger tips pattern" (Fig. 20). Muri are 0.2-0.25 $\mu \mathrm{m}$ wide, almost equal in width, they anastomose very often (the anastomose index is 6-7 per $10 \mu \mathrm{m}$ length of a murus). Muri are sometimes covered, with microgranules. Microgranules are often present also in the grooves. Perforations and microperforations usually distinct, not hidden by muri (Fig. 20).

\section{Rubus archboldianus Merrill \& Perry}

Unknown section

This New Guinean species, from eastern part of the island only, has medium-sized pollen grains (P×E: 29.6×29.5 $\mu \mathrm{m})$; meridional outline circular and sometimes slightly elliptic (Figs 25, 28, 29); P/E ratio is 1.0; equatorial outline circular to triangular in LM examinations (Fig. 27).

Apertures: Ectoapertures - colpi long, $80.4 \%$ of polar axis (Table 1), with acute ends. Colpus margins undifferentiated, not constricted; equatorial bridge distinct, with not constricted margins, which makes the bridge "opened" (Figs 25, 27).

Endoapertures - pori lalongate, not covered by equatorial bridges (Fig. 25, arrow).

Exine: The mean total thickness of the exine is $1.6 \mu \mathrm{m}$ in the centres of the mesocolpia. With SEM sublayers have not been observed. In LM examination 3 sublayers are distinct (Fig. 29, arrow).

Ornamentation: Rugulate, supratectal elements are arranged in groups, which are orientated in different directions. Between the muri slit-like spaces and perforations are present (Figs 25, 26).

\section{Rubus chrysogaeus van Royen \\ Sect. Rosaefolii}

This New Guinean species has small-sized pollen grains

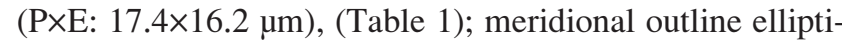
cal to circular (Figs 31, 33); equatorial outline circular to trilobed which could be observed with SEM only.

Apertures: Ectoapertures - colpi long, $82.2 \%$ of polar axis, with acute ends. Colpus margins constricted on whole its length and undifferentiated, but granulate colpus membrane is present. Equatorial bridges well developed, wide and distinct, their constricted margins making the porus unvisible (Figs 31 arrow, 32). 

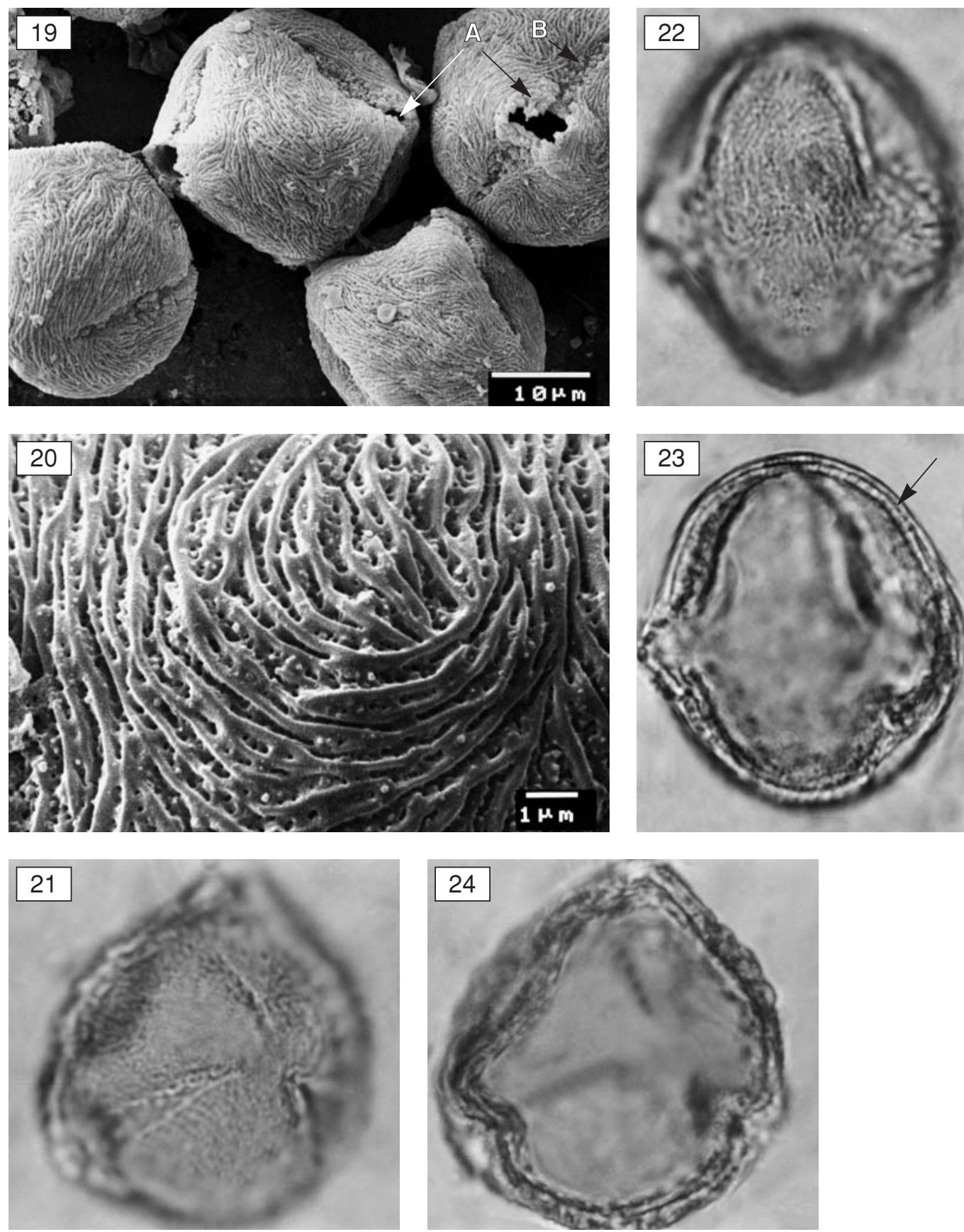

Figs 19-24. Rubus alpestris pollen.

Fig. 19. (SEM). Pollen arranged in different directions, mostly in equatorial view. Porus area (A), colpus membrane distinct (B), marked by arrows. Fig. 20. (SEM). Details of striate ornamentation, showing especially the "finger-tips" pattrern.

Fig. 21. (LM). Oblique view. Apocolpium area, acute ends of the colpi, striate ornamentation distinct $(\times 1000)$.

Fig. 22. (LM). Equatorial view. Ornamentation on the mesocolpium distinct $(\times 1000)$.

Fig. 23. (LM). Equatorial view. Outline of the grain, stratification of the exine distinct and pointed $(\times 1000)$.

Fig. 24. (LM). Oblique view. Outline of the grain distinct $(\times 1000)$.

Endoapertures - pori indistinct, hidden under the equatorial bridges (Figs 31, 32).

Exine: Total mean exine thickness is approximately 1.3 $\mu \mathrm{m}$ in the centres of mesocolpia. With SEM, sublayers have not been observed. The tectum has perforations of variable diameter (Fig. 31). In LM examination 3 sublayers are distinct (Fig. 33, arrow).
Ornamentation: Striate; muri are running mostly longitudinally, showing loosely arranged pattern with wide grooves, filled by perforations of different diameter. Muri are short, unequal in width, often merging with perforations at the basis of the muri (Fig. 31). Granules are distinct in the colpus surroundings. Muri often branched; anastomose index is 7-8 per $10 \mu \mathrm{m}$ length of a murus. 

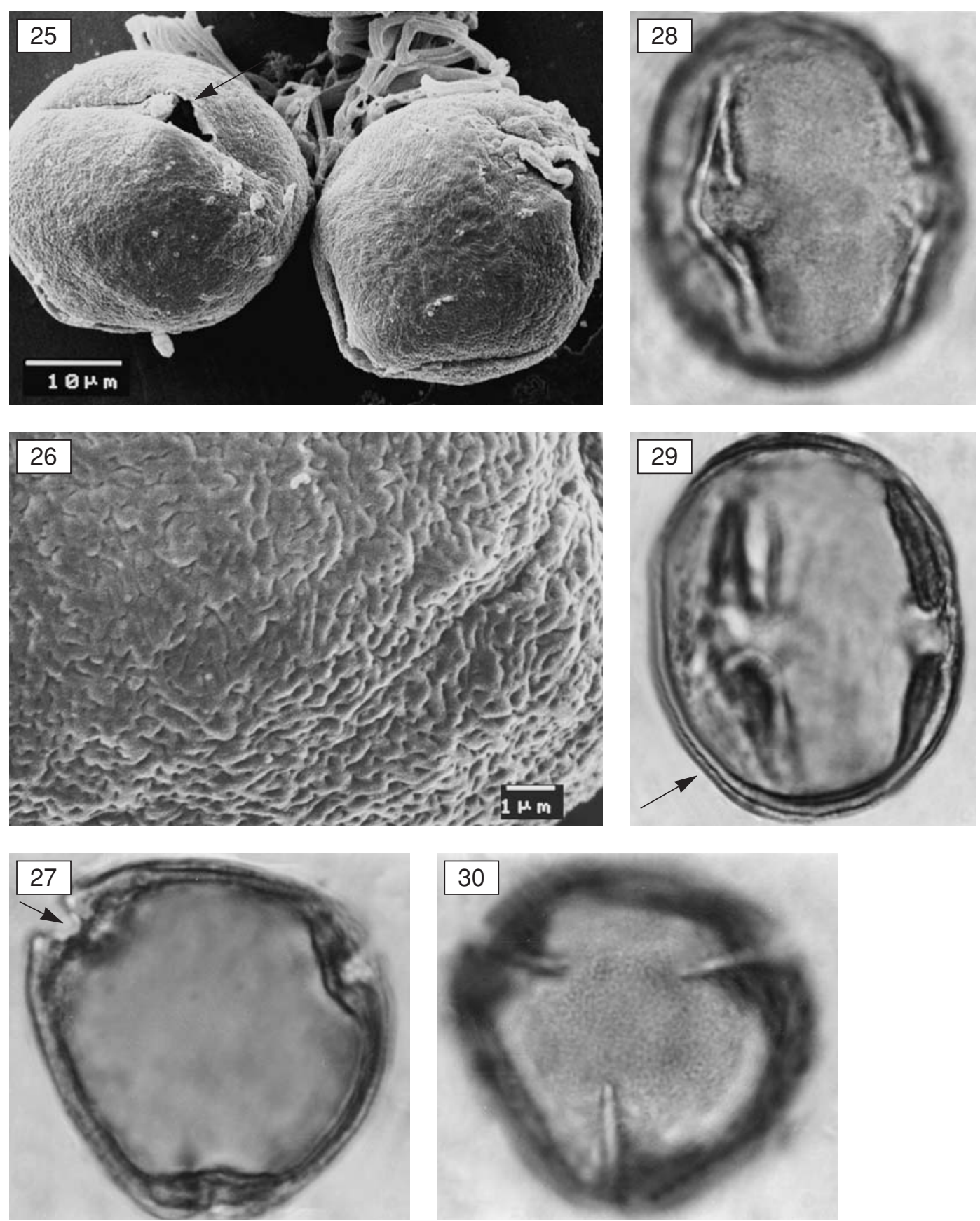

Figs 25-30. Rubus archboldianus pollen.

Fig. 25. (SEM). Pollen grains in equatorial view, porus area and porus distinct (marked by arrow).

Fig. 26. (SEM). Details of rugulate ornamentation, perforations distinct.

Fig. 27. (LM). Polar view. Equatorial outline, not constricted bridges distinct $(\times 1000)$.

Fig. 28. (LM). Equatorial view. Mesocolpium area with rugulate ornamentation distinct $(\times 1000)$.

Fig. 29. (LM). Equatorial view. Meridional outline, stratification of the grain partly distinct, marked by arrow $(\times 1000)$.

Fig. 30. (LM). Polar view. Apocolpium, polar area and acute ends of the colpi distinct $(\times 1000)$.

\section{Rubus copelandii Merill}

\section{Unknown section}

This species is only known from some mountains in Philippines. Its pollen grains are small (P×E: 25.0×21.8 $\mu \mathrm{m})$; equatorial outline circular to trilobed (Figs 34, 40); meridional outline elliptical (Figs 35, 39).

Apertures: Ectoapertures - colpi long, ca $80 \%$ of polar axis (Figs 34, 37-39), with round and acute ends (depending on the constriction of the margins). The colpus margin undifferentiated, colpus membrane granulate. The granulae are sometimes also on the margins of the colpus. The equatorial bridges present, with not constricted margins, which makes the bridges "opened" and layers of exine as well as the porus distinct (Figs 34, 35, arrows).

Endoapertures - pori lalongate, usually distinct (Figs 34, 35 , arrows).

Exine: The mean total thickness of the exine is 1.55 $\mu \mathrm{m}$ in the centres of the mesocolpia. LM examination 

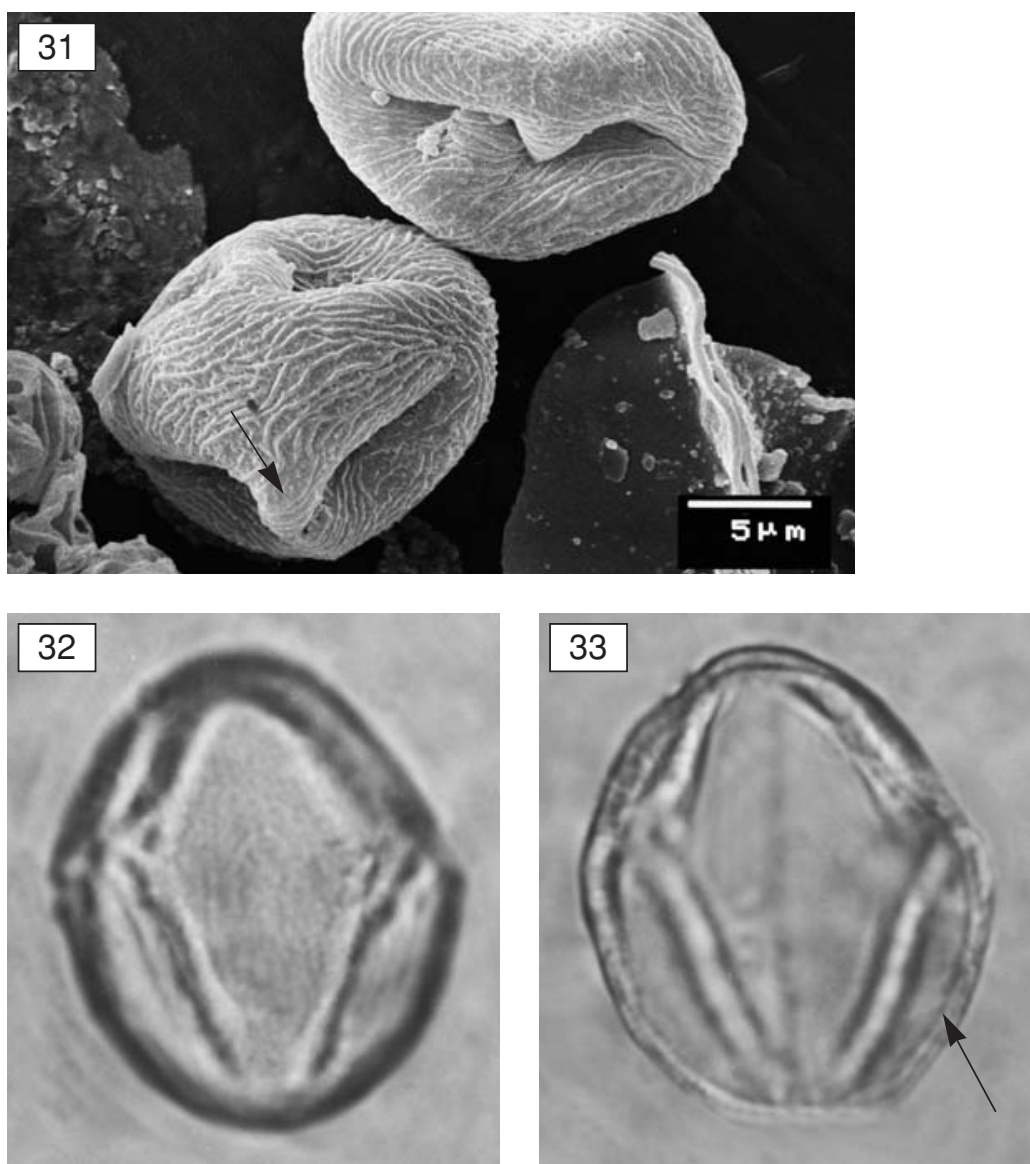

Figs 31-33. Rubus chrysogaeus pollen.

Fig. 31. (SEM). Pollen grains in equatorial view, striate ornamentation, eqauatorial bridges distinct.

Fig. 32. (LM). Equatorial view and ornamentation of mesocolpium area distinct $(\times 1000)$.

Fig. 33. (LM). Equatorial viev. Meridional outline, stratification of the exine distinct and pointed $(\times 1000)$. shows 3 sublayers (Fig. 39, arrow); with SEM, sublayers have not been observed, although the perforate tectum is quite distinct (Figs 35, 36).

Ornamentation: Compactly striate. Muri running longitudinally, of equal width, almost not separated from each other; only slit-like grooves present (Figs 35-37, 41). Muri anastomose very often. The anastomosis index is 7-9 connections per $10 \mu \mathrm{m}$ length of a murus. Thickenings are often present at connections (Fig. 36).

\section{Rubus ellipticus J.E. Smith}

Sect. Idaeanthi

This widely distributed species has small pollen grains (P×E: $20.38 \times 15.31 \mu \mathrm{m})$. Equatorial outline trilobed, rarely circular; meridional outline elliptical (Figs 42, 43).

Apertures: Ectoapertures - colpi long, 81.7\% of polar axis, with acute ends. Colpus margins constricted over their whole length, which makes the colpus membrane invisible; probably as in the other Rubus pollen the membrane is granulate. Like in other Rubus species, the colpus margins might be undifferentiated. Equatorial bridge present, well developed, with constricted margins (Figs 42, 44 arrows).

Endoapertures - pori indistinct, hidden under the equatorial bridges (Figs 42, 44).

Exine: The mean total thickness of the exine is $1.4 \mu \mathrm{m}$ in the centres of the mesocolpia. LM examination shows 3 sublayers (Fig. 43). With SEM, sublayers have not been observed, but perforations in the tectum are distinct (Fig. 42).
Ornamentation: Compactly striate. Muri running longitudinally and curving towards the colpus slightly, of almost equal width, except for places of anastomoses. The anastomosis index is about 6-8 connections per $10 \mu \mathrm{m}$ length of a murus. Muri are compactly arranged and the perforations are distinct in the grooves (Fig. 42).

Remarks: Regarding ornamentation, R. ellipticus is similar to $R$. copelandii, but the equatorial bridges are well developed and constricted.

\section{Rubus ferdinandi-muelleri Focke \\ Sect. Pungentes}

Pollen grains of this New Guinean species are small (P×E: $17.27 \times 11.20 \mu \mathrm{m})$. Equatorial outline based on SEM observation circular to trilobed; meridional outline elliptical (Fig. 45A). Unfortunately SEM and LM photographs of polar view are not available.

Apertures: Ectoapertures - colpi long, 81\% of polar axis, with rounded ends. Colpus margins undifferentiated and constricted along their length. A few granules are occasionally situated there. Colpus membrane granulate. Equatorial bridges have not been observed with SEM (Fig. 45A), but in LM they were visible (Fig. 47 arrow). Endoapertures - pori indistinct because of constricted colpus margins (Fig. 45).

Exine: The mean total thickness of the exine is $1.2 \mu \mathrm{m}$ in the centres of the mesocolpia. LM examination shows 3 layers of the exine (Fig. 48). SEM, sublayers have not been 

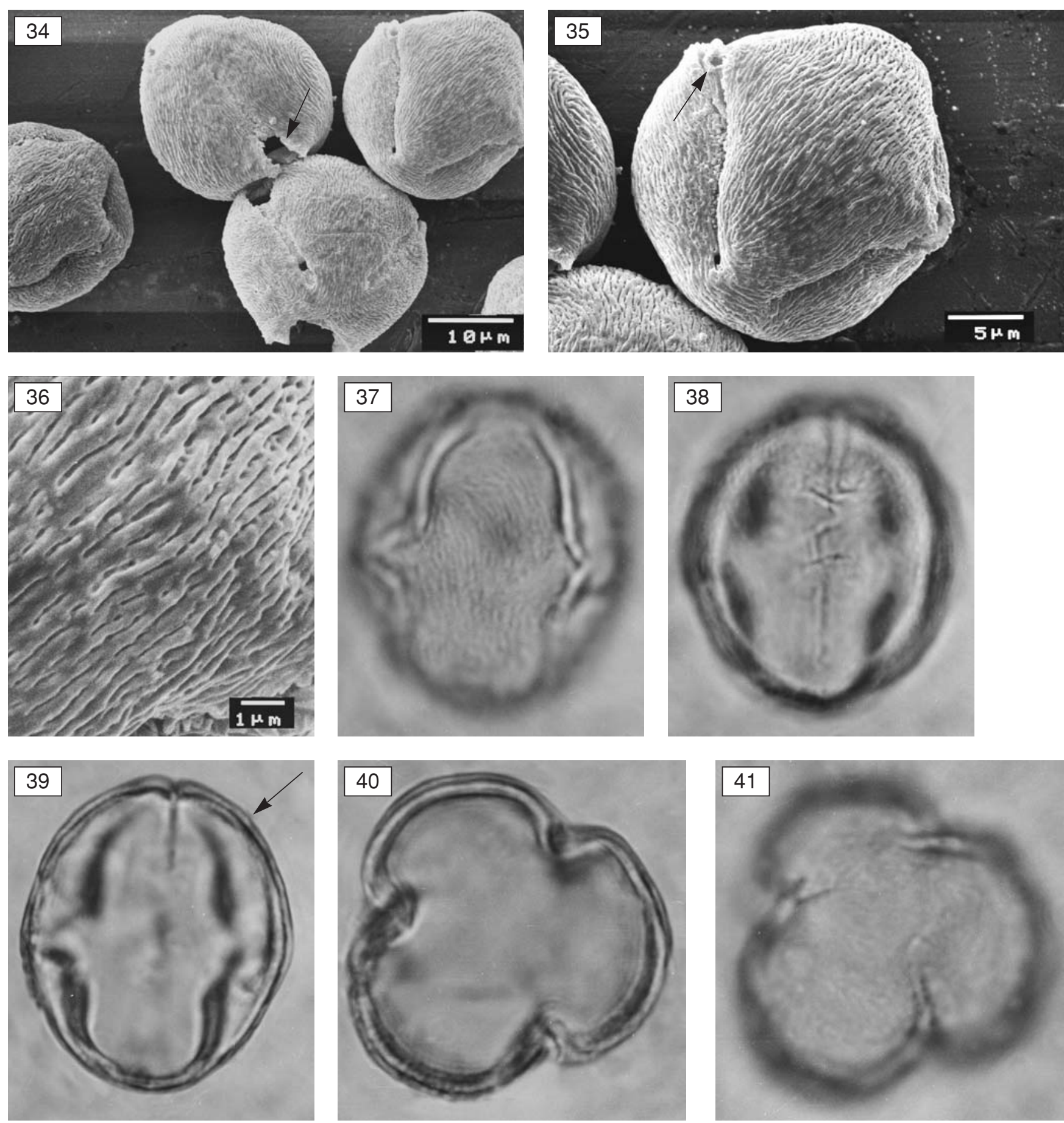

Figs 34-41. Rubus copelandii pollen.

Fig. 34. (SEM). Pollen grains in various arrangement. Porus well distinct and marked.

Fig. 35. (SEM). Oblique orientation of the grain. Striate ornamentation, not constricted bridges and porus distinct and marked.

Fig. 36. (SEM). Details of striate ornamentation.

Fig. 37. (LM). Equatorial view. Ornamentation on mesocolpium distinct $(\times 1000)$.

Fig. 38. (LM). Equatorial view, equatorial bridges well distinct $(\times 1000)$.

Fig. 39. (LM). Meridional outline of the grain in equatorial view. Stratification of exine distinct and marked $(\times 1000)$.

Fig. 40. (LM). Equatorial outline of the grain in polar view $(\times 1000)$.

Fig. 41. (LM). Polar view. Ornamentation on the polar area and apocolpium distinct $(\times 1000)$.

observed, but perforations in the tectum are obviously recorded (Fig. 46).

Ornamentation: Striate-like pattern with elements arranged mostly longitudinally. Muri very thick and of irregular width, with many thickenings along the muri or at the places of connections. There are bacula-like elements along the colpus margins (Fig. 45B, arrow).

Remarks: Thick, irregular muri have not been observed in the subgenera Micranthobatus, Chamaebatus, Idaeobatus (Tomlik-Wyremblewska 1995, 2000). 

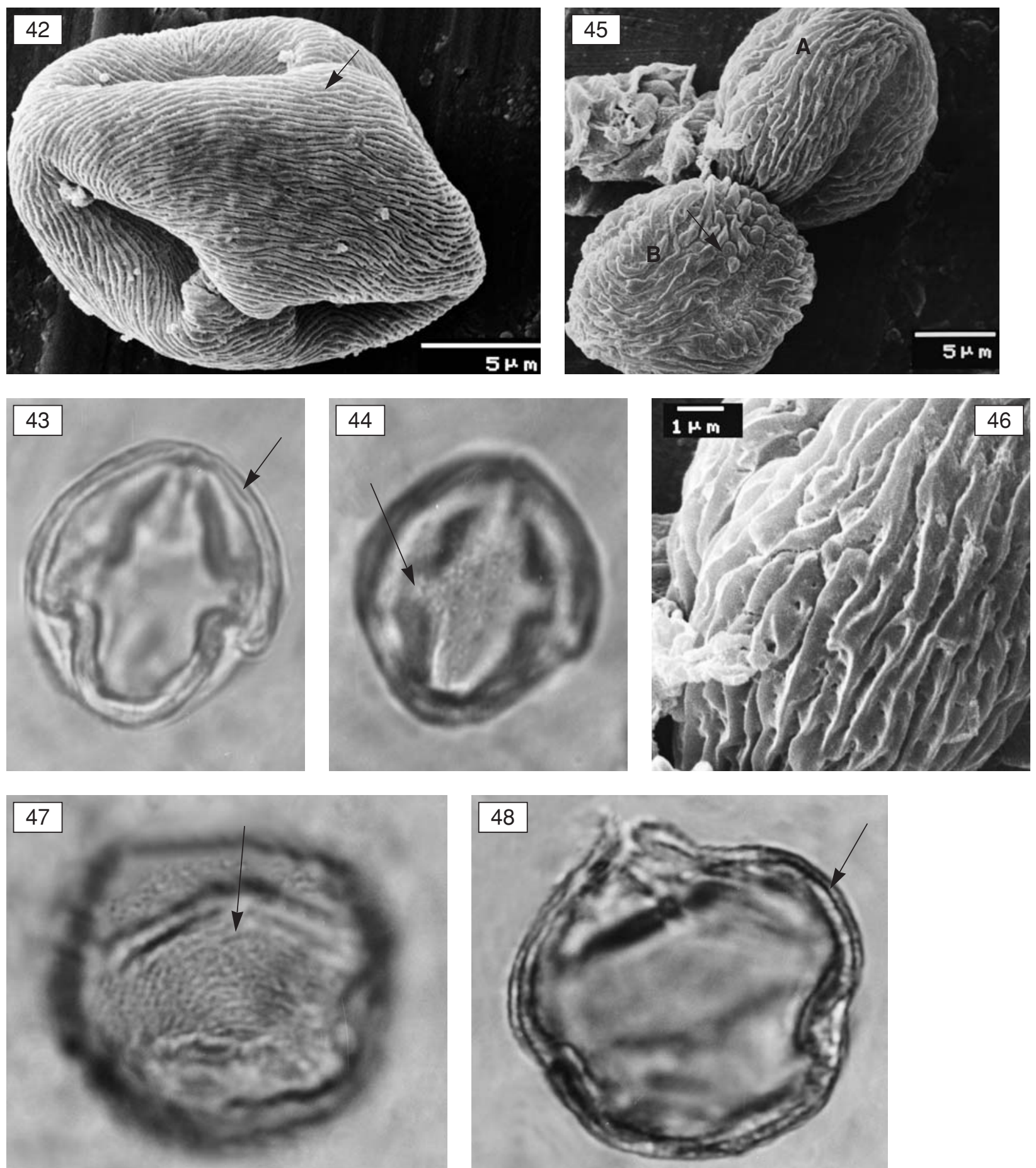

Figs 42-44. Rubus ellipticus pollen.

Fig. 42. (SEM). Equatorial view and striate ornamentation of the grain, well developed bridges distinct.

Fig. 43. (LM). Equatorial view. Meridional outline. Stratification of the exine distinct and marked $(\times 1000)$.

Fig. 44. (LM). Equatorial view. Ornamentation and equatorial bridges consticted distinct $(\times 1000)$.

Figs 45-48. Rubus ferdinandi-muelleri pollen.

Fig. 45. (SEM). Pollen grain in oblique (B) and equatorial (A) view.

Fig. 46. (SEM). Details of the striate ornamentation; irregular muri distinct.

Fig. 47. (LM). Oblique orientation of the grain. Ornamentation on the mesocolpium distinct $(\times 1000)$.

Fig. 48. (LM). Oblique orientation of the grain, outline and stratification of the exine distinct and marked $(\times 1000)$.

Rubus fraxinifolius Poiret

Sect. Rosaefolii

This widely distributed species has small pollen grains (P×E: 17.9×14.9 $\mu \mathrm{m}$ ); equatorial outline circular (Figs 49C,
54), meridional outline elliptical (Figs 49A, 53); (P/E index: 1.3), (Table 1).

Apertures: Ectoapertures - colpi long, $88 \%$ of polar axis, with acute ends. Colpus margins undifferentiated, fi- 

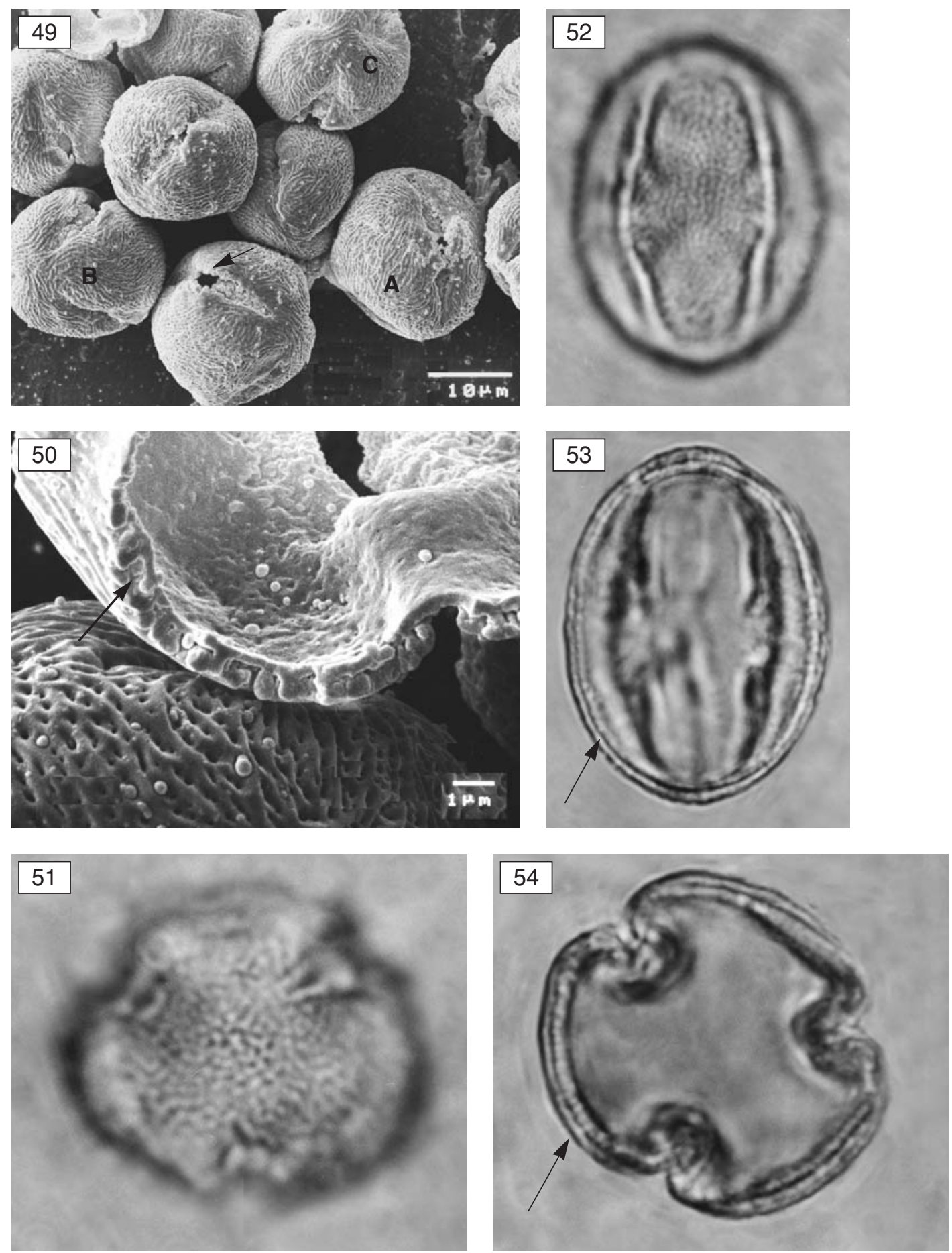

Figs 49-54. Rubus fraxinifolius pollen.

Fig. 49. (SEM). Pollen arranged in different positions. A - Equatorial view. B - Oblique view. Equatorial bridges stretched, porus distinct (marked by arrow). Fig. 50. (SEM). Details of ornamentation. Stratification of exine distinct and marked (arrow).

Fig. 51. (LM). Polar view, polar area, ornamentation distinct $(\times 1000)$.

Fig. 52. (LM). Equatorial view of the grain. Ornamentation on mesocolpium distinct $(\times 1000)$

Fig. 53. (LM). Meridional outline of pollen in equatorial view. Stratification of the exine distinct, marked by arrow $(\times 1000)$.

Fig. 54. (LM). Equatorial outline. Stratification of the exine distinct and marked, equatorial bridges stretched $(\times 1000)$.

nely undulated, constricted slightly in the equator. Equatorial bridges relatively poorly marked, which makes the porus visible (Figs 49, 52). Endoapertures - pori lalongate, partly hidden by equatorial bridge (Fig. 49 , marked by arrow). Microgranules are often visible in porus and colpus surroundings (Figs 49, 50).
Exine: The mean total thickness of the exine is $1.3 \mu \mathrm{m}$ in the centres of the mesocolpia. LM and SEM examination shows 3 distinct units: nexine, infratectum (columellate layer) and tectum with supratectal elements on SEM (Fig. 50 arrow) and LM (Figs 53, 54 arrows). 

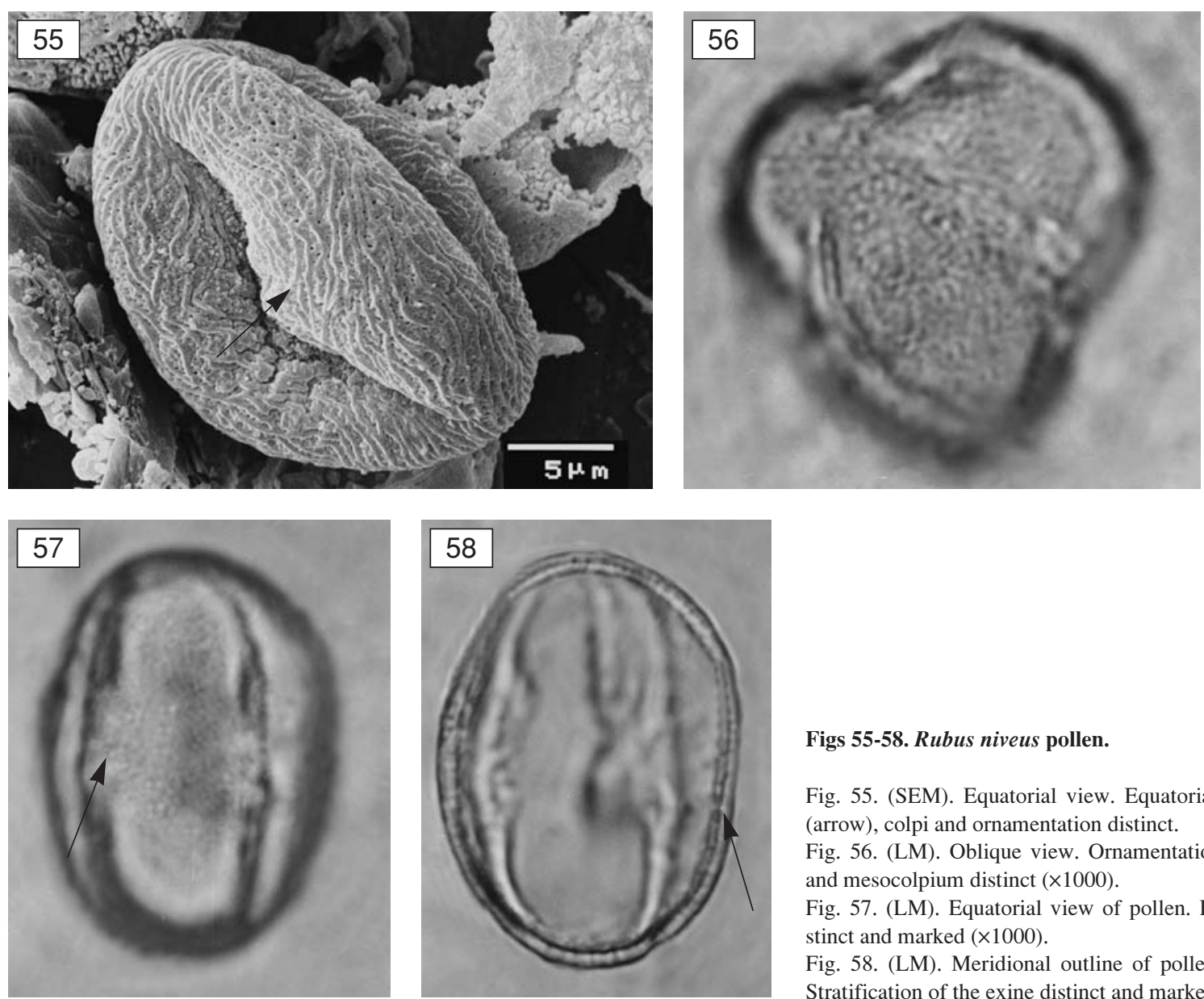

Figs 55-58. Rubus niveus pollen.

Fig. 55. (SEM). Equatorial view. Equatorial bridges constricted (arrow), colpi and ornamentation distinct.

Fig. 56. (LM). Oblique view. Ornamentation of the apocolpium and mesocolpium distinct $(\times 1000)$.

Fig. 57. (LM). Equatorial view of pollen. Equatorial bridges distinct and marked $(\times 1000)$.

Fig. 58. (LM). Meridional outline of pollen in equatorial view. Stratification of the exine distinct and marked $(\times 1000)$.

Ornamentation: Striate pattern with muri arranged meandrically (Figs 49-52). The anastomosis index is average 7-9 per $10 \mu \mathrm{m}$ length of a murus. Grooves with perforations and often filled with microgranules (Fig. 50).

\section{Rubus niveus Thunb. (collected as R. leucocarpus Arnott) Sect. Idaeanthi}

This widely distributed species in Malesia and continental Asia has small pollen grains (P×E: $24.95 \times 18.9 \mu \mathrm{m})$. In LM and SEM examinations, equatorial outline circular to trilobed, what could be seen in oblique view also on Fig. 56; meridional outline elliptical (Figs 55, 58); P/E ratio 1.3.

Apertures: Ectoapertures - colpi long, $81.6 \%$ of polar axis, with acute ends. Colpus margins undifferentiated, slightly constricted along their length. Colpus membrane granulate; granules are distinct also on the colpus margins. Equatorial bridges hardly marked (Figs 55, 57, marked by arrows).

Endoapertures - pori not distinct, because of constricted colpus margins (Fig. 55).

Exine: Mean total thickness of the exine is $1.4 \mu \mathrm{m}$ in the centres of the mesocolpia. LM examination shows 3 layers of the exine (Fig. 58). SEM sections have not been observed, although SEM details show a perforate tectum (Fig. 55).

Ornamentation: Loosely striate. Muri are arranged mostly longitudinally, turning towards the colpi. Muri separate wide grooves, filled with perforations. Muri anastomose
3-5 times in the length of $10 \mu \mathrm{m}$ of a murus. They are equal in width except for the place of the connections, where thickenings are occasionally observed (Fig. 55). Granules are observed in the grooves along the colpus margins.

\section{Rubus lorentzianus Pulle \\ Unknown section}

This New Guinean species has medium-sized pollen grains $(\mathrm{P} \times \mathrm{E}$ : $34.5 \times 24.3 \mu \mathrm{m})$; equatorial outline circular to trilobed (Fig. 62), meridional outline elliptical (Figs 59, 60, 64, Table 1).

Apertures: Ectoapertures - colpi long, $86.2 \%$ of polar axis, with acute ends, constricted along all their length. Colpus margins undifferentiated. Colpus membrane granulate. Equatorial bridges distinct; their margins are constricted (Figs 59, 65 arrow).

Endoapertures - pori indistinct because of usually "closed" equatorial bridges (Figs 59, 63, 65).

Exine: Mean total thickness of the exine is $1.6 \mu \mathrm{m}$ in the centres of the mesocolpia (Table 1, Figs 62, 64, marked by arrows). Details of exine stratification unknown, but the perforate tectum is distinct (Fig. 61).

Ornamentation: Striate-scabrate with muri running mostly perpendicular to the polar axis, although some change of arrangement of the muri can be observed, especially around the equator (Figs 59, 60, 63). Muri are thin in comparison to the previous species, equal in width, loosely arran- 

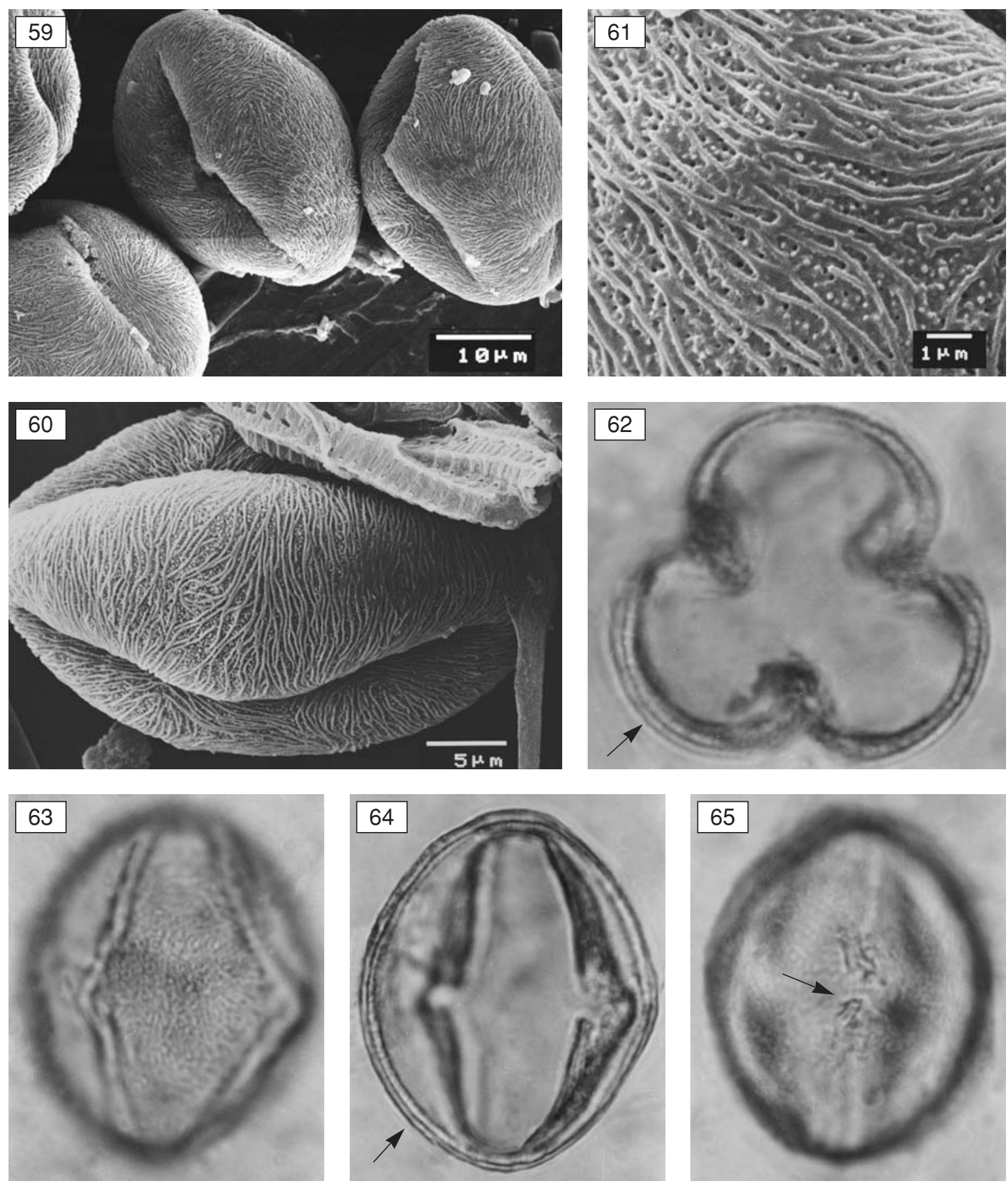

Figs 59-65. Rubus lorentzianus pollen.

Fig. 59. (SEM). Group of the pollen in oblique and equatorial view. Equatorial bridges constricted deep in the colpus.

Fig. 60. (SEM). Equatorial view of the grain. Striate-scabrate ornamentation distinct.

Fig. 61. (SEM). Details of the striate-scabrate ornamentation.

Fig. 62. (LM). Polar view, equatorial outline of pollen, stratification of the exine distinct and marked $(\times 1000)$.

Fig. 63. (LM). Equatorial view, ornamentation distinct $(\times 1000)$.

Fig. 64. (LM). Meridional outline of pollen in equatorial view, stratification of the exine distinct $(\times 1000)$.

Fig. 65. (LM). Equatorial view, equatorial bridges constricted, marked by arrow $(\times 1000)$.

ged on the mesocolpia and apocolpia. Granules occur between the muri, in "grooves", here called the lumina, and constitute supratectal elements. Muri often anastomose; the anastomosis index is 5-8 connections per $10 \mu \mathrm{m}$ length of a murus (Figs 60, 61).

Remarks: One of the biggest pollen grains among the examined species.

\section{R. macgregorii $\mathrm{F}$. von Mueller} Unknown section

The occurrence of this species is restricted to mountains in Celebes and Papua New Guinea. Pollen grains are \pm medium-sized $(\mathrm{P} \times \mathrm{E}$ : $29.8 \times 28.9 \mu \mathrm{m})$, equatorial outline circular to trilobed, what could be seen on Fig. 68 and 71; meridional outline circular to slightly elliptical (Fig. 66). $\mathrm{P} / \mathrm{E}$ ratio 1.03 shows circular shape of the grain (Table 1 ). 

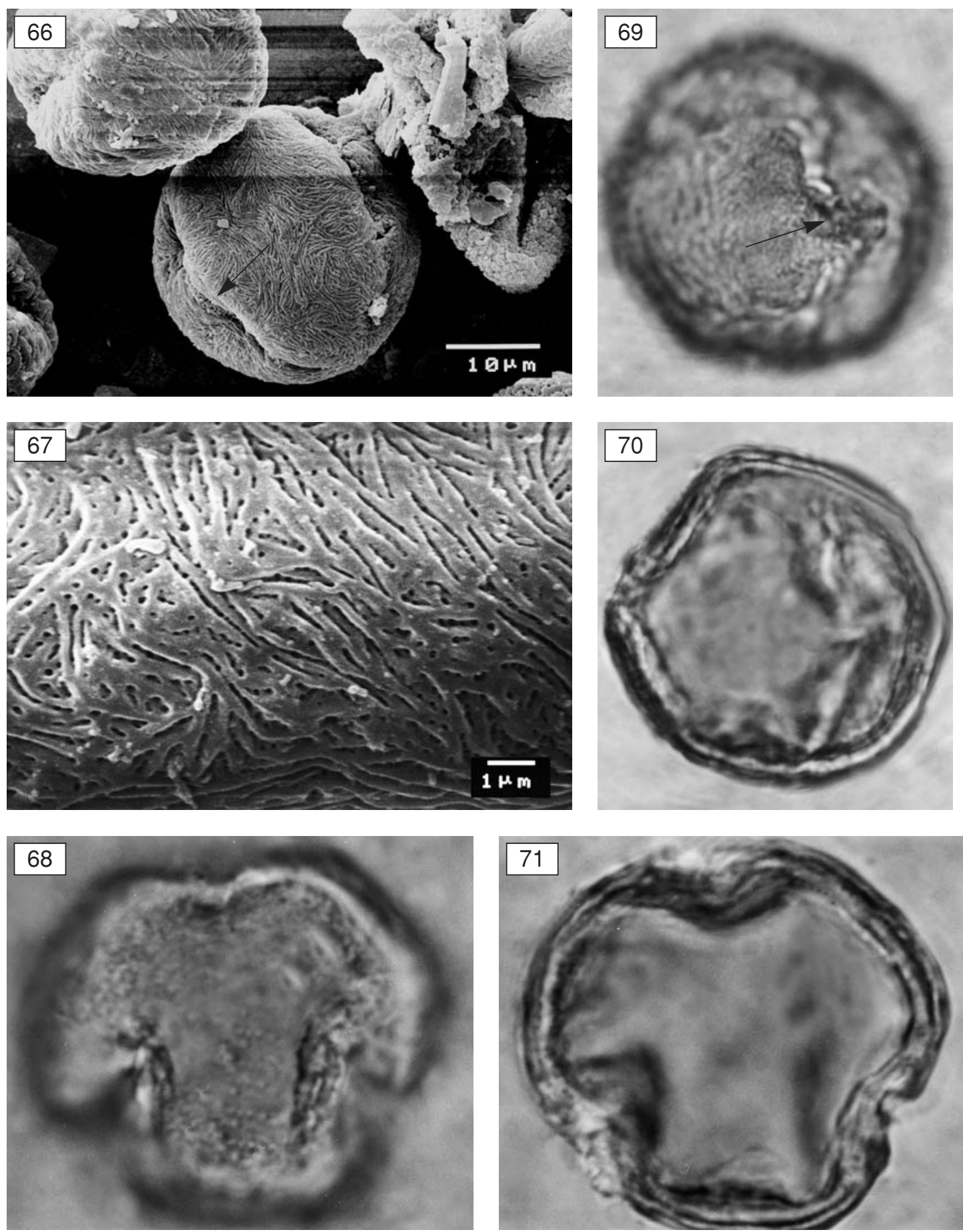

Figs 66-71. Rubus macgregorii pollen.

Fig. 66. (SEM). Equatorial view of the pollen. Equatorial bridges constricted and marked.

Fig. 67. (SEM). Details of rugulate-striate ornamentation.

Fig. 68. (LM). Oblique view of the pollen, ornamentation on the polar area distinct $(\times 1000)$.

Fig. 69. (LM). Equatorial view of the pollen, ornamentation, equatorial bridge distinct and marked $(\times 1000)$.

Fig. 70. (LM). Outline of pollen in equatorial view $(\times 1000)$.

Fig. 71. (LM). Outline of the pollen in oblique view referring to Fig. 68. Stratification of the exine partly distinct $(\times 1000)$.

Apertures: Ectoapertures - colpi long, with acute ends, $80.2 \%$ of polar axis, usually constricted along the ends. Colpus margins undifferentiated and folded inwards (Figs $66,69)$. Colpus membrane granulate. Equatorial bridges distinct with their margins constricted (Fig. 66, 69 arrows).

Endoapertures - pori indistinct because of equatorially constricted bridges (Fig. 66, marked by arrow).
Exine: The total thickness of the exine is $2.0 \mu \mathrm{m}$ in the centres of the mesocolpia (Figs 70, 71). Exine is composed of 3 sublayers. Tectum perforate; perforations $0.1-0.15$ $\mu \mathrm{m}$ in diameter, often covered by muri (Fig. 67).

Ornamentation: Faintly rugulate or irregularly rugulatestriate. Muri arranged in triangular groups, of different orientation, usually close together. Grooves narrower than the mu- 

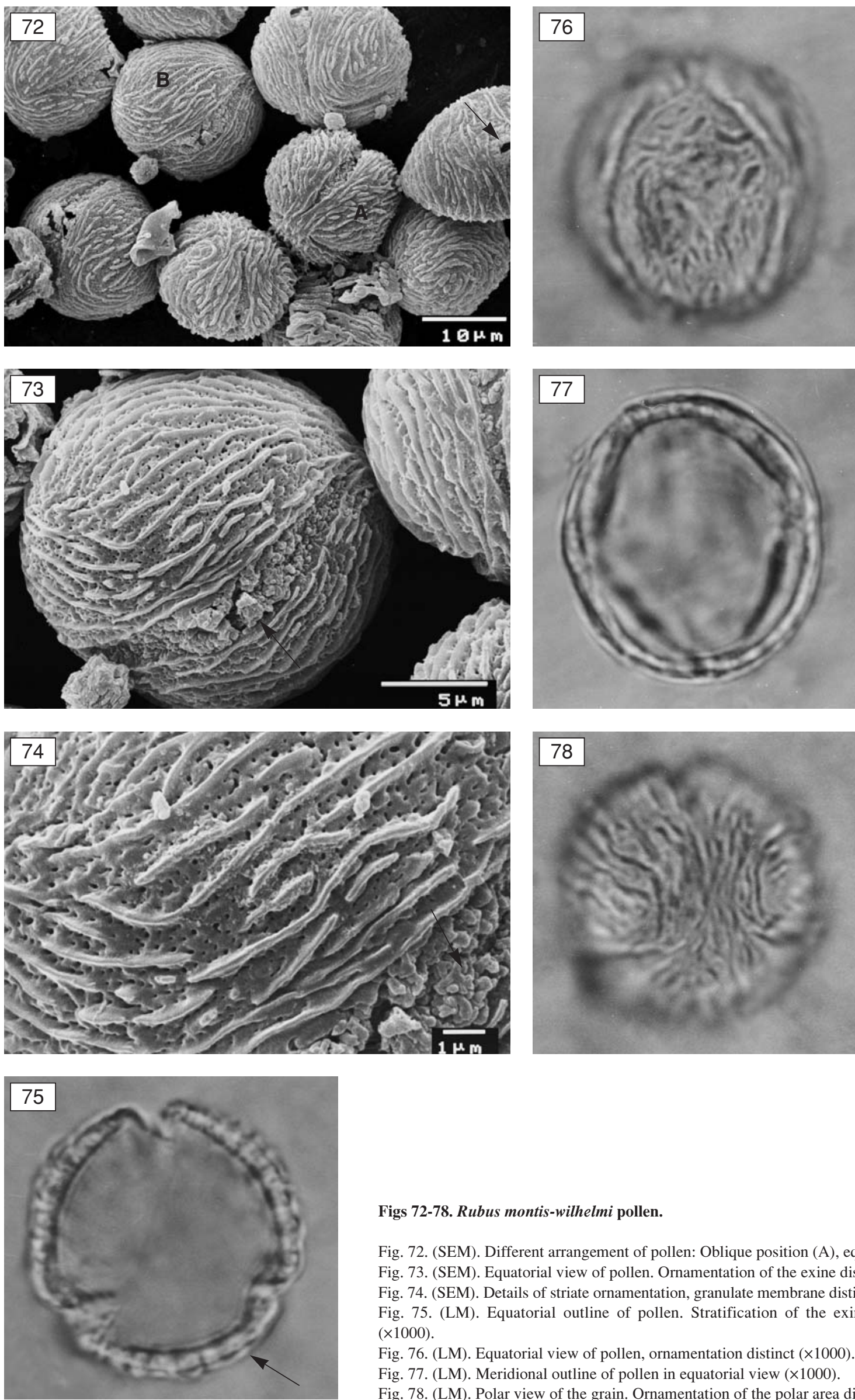

Figs 72-78. Rubus montis-wilhelmi pollen.

Fig. 72. (SEM). Different arrangement of pollen: Oblique position (A), equatorial position (B). Fig. 73. (SEM). Equatorial view of pollen. Ornamentation of the exine distinct, porus marked. Fig. 74. (SEM). Details of striate ornamentation, granulate membrane distinct and marked (arrow). Fig. 75. (LM). Equatorial outline of pollen. Stratification of the exine distinct and marked ( $\times 1000)$.

Fig. 76. (LM). Equatorial view of pollen, ornamentation distinct $(\times 1000)$

Fig. 77. (LM). Meridional outline of pollen in equatorial view $(\times 1000)$.

Fig. 78. (LM). Polar view of the grain. Ornamentation of the polar area distinct $(\times 1000)$. 

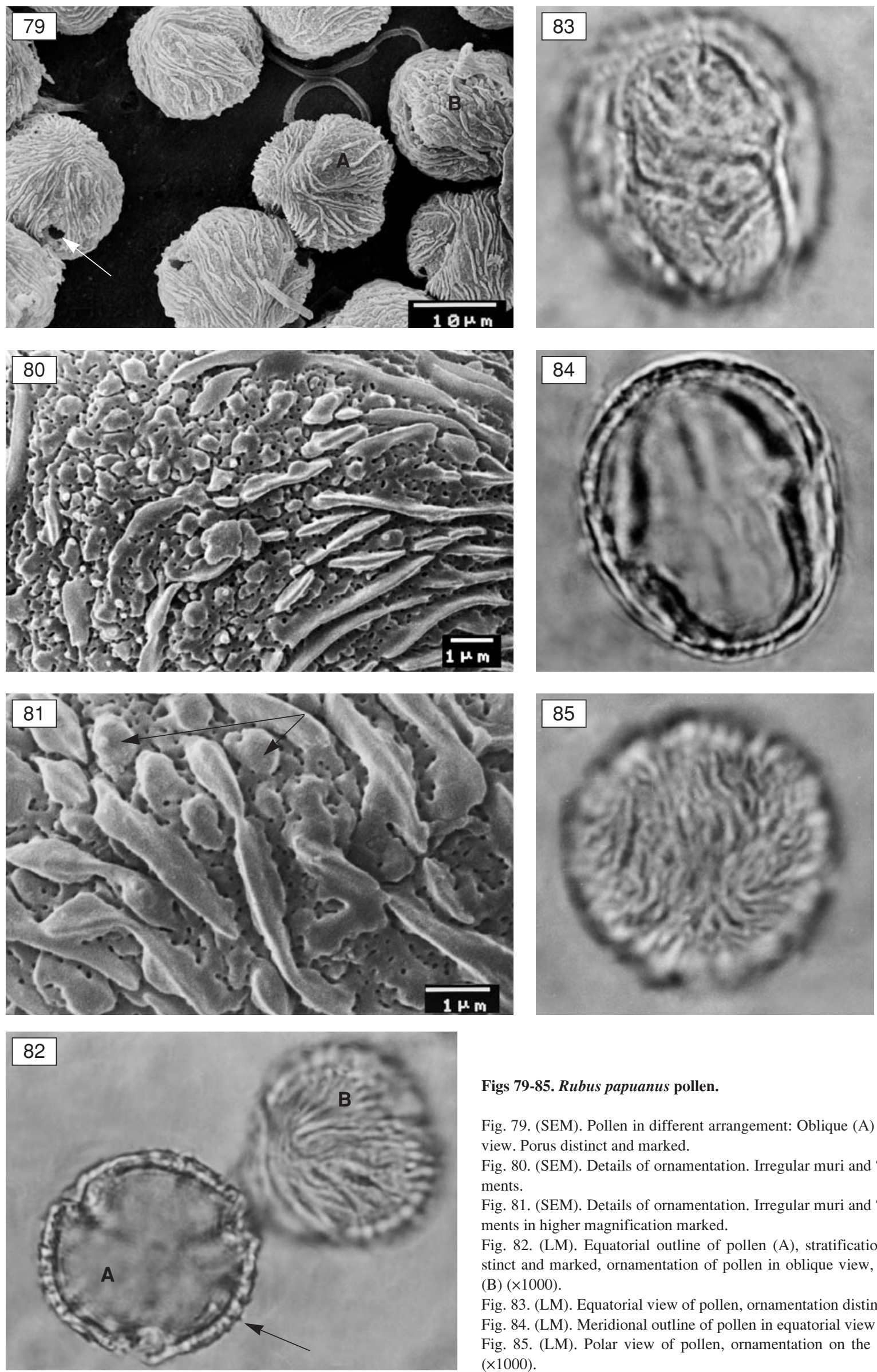

Figs 79-85. Rubus papuanus pollen.

Fig. 79. (SEM). Pollen in different arrangement: Oblique (A) and equatorial (B) view. Porus distinct and marked.

Fig. 80. (SEM). Details of ornamentation. Irregular muri and "baculae-like" elements.

Fig. 81. (SEM). Details of ornamentation. Irregular muri and "baculae-like" elements in higher magnification marked.

Fig. 82. (LM). Equatorial outline of pollen (A), stratification of the exine distinct and marked, ornamentation of pollen in oblique view, polar area distinct (B) $(\times 1000)$.

Fig. 83. (LM). Equatorial view of pollen, ornamentation distinct $(\times 1000)$

Fig. 84. (LM). Meridional outline of pollen in equatorial view $(\times 1000)$.

Fig. 85. (LM). Polar view of pollen, ornamentation on the polar area distinct $(\times 1000)$. 
ri and elongated, filled up by perforations. Muri are short, Lshaped or stright, 1-3.5 $\mu \mathrm{m}$ long, sometimes anastomosing; the range is $1-3$ per $10 \mu \mathrm{m}$ length of a murus (Figs 66, 67).

Remarks: Pollen of very regular shape and very thick exine. This type of ornamentation has been reported in my studies on Rubus pollen for the first time.

\section{Rubus montis-wilhelmi van Royen \\ Unknown section}

This bramble from New Guinea has small pollen grains, P×E: $17.2 \times 16.6 \mu \mathrm{m}$ (Table 1 ), of very regular shape, almost without variation (Table 1); equatorial outline circular to 3-lobed (Figs 72A, 75), meridional outline almost circular, $\mathrm{P} / \mathrm{E}$ ratio 1.04 (Table 1, Figs $72 \mathrm{~B}, 73,77$ ).

Apertures: Ectoapertures - colpi long, 90.1\% length of polar axis, with acute ends. Colpus margins undifferentiated and distinct, rarely folded inwards. Colpus is not constricted, the equatorial bridge very faintly developed, not constricted (stretched or opened) (Figs 72, 73). The granulate colpus membrane is quite distinct (Figs 73, 74, marked by arrow).

Endoapertures - pori not covered by the equatorial bridge, distinct in SEM and LM observations, usually lalongate in shape (Figs 72, 73, marked by arrows). SEM photos show pori covered by granules (Figs 72, 73).

Exine: Total thickness of the exine is $1.3 \mu \mathrm{m}$ in the centres of the mesocolpia. In LM examination 3 sublayers are distinct (Figs 75, marked by arrow, 77). These layers have not been measured, but a perforate tectum is distinct (Figs $73,74)$. Perforations are up to $0.2 \mu \mathrm{m}$ in diameter and situated in the grooves.

Ornamentation: Striate, with distinct, relatively thick comparing with the previous species, high muri, loosely arranged on the tectum, usually running longitudinally. Muri are short and do not anastomose. Perforations of different diameter are filling up relatively wide grooves (Fig. 74).

Remarks: Pollen grains very uniform in size and shape, comparable with pollen of $R$. papuanus.

\section{Rubus papuanus Schlechter ex Diels \\ Unknown section}

This species occurs in eastern part of New Guinea. Pollen grains are small, (P×E: $17.8 \times 17.2 \mu \mathrm{m})$, very regular in shape and almost without variation (Table 1, Fig. 79). Equatorial outline circular to trilobed (Figs 79A, 82A). Meridional outline circular, $\mathrm{P} / \mathrm{E}$ ratio 1.03 indicates almost spherical shape (Figs 79B, 84).

Apertures: Ectoapertures - colpi short, ca 75\% length of polar axis, with acute ends. Colpus is not constricted; equatorial bridges faintly developed, stretched. The porus area distinct. Membrane of the colpus granulate; granules are big (Fig. 79).

Endoapertures - pori lalongate and distinct (Fig. 79, marked by arrow).

Exine: Total thickness of the exine is $1.2 \mu \mathrm{m}$ in the centres of the mesocolpia (Figs 82A, 84). In LM examination
3 sublayers are distinct. These layers have not been measured, but a perforate tectum is distinct (Figs 80, 81). Perforations are less than $0.1 \mu \mathrm{m}$ in diameter and are situated in the grooves.

Ornamentation: The surface of the pollen presents not a regular sculpture. It could be classified as a mixture of striate and granulate-baculate pattern (Figs 79-81, 82B, 83, $85)$. The granules are different in size, some of them are so big as baculae in baculate pattern in R. chamaemorus (Fig. 81 , marked by arrows).

Remarks: Pollen grains very uniform in size and shape, comparable with pollen of $R$. montis-wilhelmi.

\section{DISCUSSION}

The Malesian Rubus species grouped in the subgenera Chamaebatus and Idaeobatus, as described by Zandee and Kalkman (1981), present a rather great diversity both in size and in shape of their pollen grains. All species examined have the Rubus pollen type. They are isopolar, radially symmetrical, 3-colporate, according to Erdtman (1952), Reitsma (1966) and Eide (1981). The main ideas on pollen morphology of the examined species are presented below.

\section{Shape and size}

The equatorial outline of the grains is circular to 3-lobed, whereas the meridional outline is mainly elliptical and sometimes circular. The exceptions are Rubus archboldianus, $R$. montis-wilhelmi and R. papuanus (subgenus Idaeobatus) which have an almost circular meridional outline* (Table 1) and a spherical shape.

The size of the grains is in the range from small to medium. The medium-sized class is represented by the species of subgenus Chamaeobatus and some of subgenus Idaeobatus, e.g.: Rubus alpestris, R. archboldianus, R. lorentzianus and $R$. macgregorii. The size of the medium-sized grains is 28-38 $\mu \mathrm{m}$ for the polar axis "P" and 25-31 $\mu \mathrm{m}$ for the equatorial diameter "E" (Table 1). The other grains should be classified as small according to Erdtman (1.c.). The largest pollen was found in $R$. lorentzianus (range $P \times E$ : $32-38 \mu \mathrm{m} \times 24-28 \mu \mathrm{m}$, average $34.5 \times 26.2$ ), whereas the smallest was observed in $R$. montis-wilhelmi $(\mathrm{P} \times \mathrm{E}$ : 17.2×16.6 $\mu \mathrm{m})$, R. papuanus $(\mathrm{P} \times \mathrm{E}: 17.7 \times 17.2 \mu \mathrm{m})$ and in $R$. chrysogaeus $(\mathrm{P} \times \mathrm{E}: 17.4 \times 16.2 \mu \mathrm{m})$. The most uniformlysized grains are presented by $R$. montis-wilhelmi (the standard deviation is only $0.16 \mu \mathrm{m}$ for polar axis). The most variable pollen in size belongs to $R$. calycinus and $R$. pectinellus, both of subgenus Chamaebatus, and to R. alpestris, $R$. ellipticus and $R$. lorentzianus of subgenus Idaeobatus, where the standard deviation for polar axis $(\mathrm{P})$ is from 1.55 to $2.18 \mu \mathrm{m}$ (Table 1). Both LM and SEM examinations show the variation between and within the species. The $\mathrm{P} / \mathrm{E}$ index indicates the ellipsoid grains in the most of the species except the circular grains described above*.

\section{Apertures}

Ectoapertures: Except Rubus papuanus (ca 75\% length of polar axis), all examined Rubus species tend to have long colpi measuring $81-85 \%$ length of the polar axis. Colpi are approximately $4.4 \mu \mathrm{m}$ wide in the widest part. The 
longest colpi occur in $R$. lorentzianus, which cover $86.2 \%$ length of polar axis; the shortest in $R$. papuanus: $75 \%$ length of polar axis. The furrows taper into acute ends in most of the examined species. The colpus membrane is granulate in all species, which is distinct in SEM microphotographs. Equatorial bridges are present in all species, although in some of them they are not well developed. In such species as $R$. pectinellus, of subgenus Chamaebatus, and $R$. montis-wilhelmi and R. papuanus, of subgenus Idaeobatus, there are almost no bridges. Membrane granules cover the pore area. The bridges are stretched (opened) in such species as $R$. alpestris, $R$. archboldianus and $R$. copelandii of subgenus Idaeobatus. $R$. calycinus of subgenus Chamaebatus shows the equatorial bridge constricted deep in the colpus. The other species of subgenus Idaeobatus show well developed equatorial bridges, often constricted deep in the colpus..

Endoapertures: Lalongate pori were found in R. pectinellus, of subgenus Chamaebatus, and in $R$. alpestris, $R$. archboldianus, $R$. copelandii, $R$. montis-wilhelmi and $R$. papuanus, of subgenus Idaeobatus. In the other species, pori are hidden under the equatorial bridges and they are not seen neither in LM nor in SEM.

\section{Exine}

The exine thickness in the centres of the mesocolpia measured in glycerine-jelly showed variation. The range was 1.22-2.04 $\mu \mathrm{m}$ for different species. The thickest exine was observed in Rubus pectinellus, of subgenus Chamaebatus, and in $R$. macgregorii, of subgenus Idaeobatus (Table 1); whereas the thinner exine was found in $R$. papuanus of subgenus Idaeobatus. The thickness of the exine depends partly on height of the supratectal elements, which differs from species to species.

\section{Ornamentation}

The species studied generally show the striate pattern. Variation was present in subgenus Idaeobatus, where species showed several modifications of the striate pattern. Some of these patterns have not been reported earlier for Rubus.

1. Rubus archboldianus - rugulate pattern, supratectal elements arranged in groups, oriented in different directions.

2. R. lorentzianus - striate-scabrate pattern, muri alternating with relatively wide "grooves", which could be described here as lumina, filled with granules. Muri are not running longitudinally, mostly perpendicular to the polar axis.

3. R. macgregorii - faintly rugulate or irregular striaterugulate pattern, muri arranged in triangular groups.

4. R. alpestris - striate pattern with muri oriented meandrically.

5. R. ferdinandi-muelleri R. montis-wilhelmi, R. papua$n u s$, - striate pattern with muri of variable length, width and height, sometimes grooves filled with granules of different size, or high and short muri resembling the baculae in baculate pattern are present ( $R$. papuanus).

6. $R$. acuminatissimus, $R$. leucocarpus - striate pattern with thin muri loosely spread on the exine surface, oriented in different directions.

\section{CONCLUSIONS}

The pollen of Rubus of subgenus Chamaebatus represented by two Malesian species (R. calycinus and $R$. pectinel$l u s)$ shows a striate ornamentation pattern with diversity in the orientation of the muri, their width and the anastomosing pattern. The species of this subgenus are small, mostly herbaceous to slightly woody plants, with creeping stems and simple leaves, occurring in disjunct mountain areas. $R$. calycinus comes from the Himalaya region (Nepal), NE India, N Burma, S China and E Java, whereas $R$. pectinellus occurs mainly in south-eastern part of China, Taiwan, Japan and Philippines. From the morphological point of view of pollen, they could be regarded as related species, although their area of distribution is not the same.

The species of subgenus Idaeobatus have been classified into nine sections according to Focke $(1911,1914)$. The Malesian species do not belong to one section and according to Zandee and Kalkman (1981), on the basis of morphological features, they can be grouped as follows:

1. Species with pinnate leaves, represented by Rubus chrysogaeus and $R$. fraxinifolius, belong to section Rosaefolii, and $R$. ferdinandi-muelleri to section Pungentes. $R$. montis-wilhelmi and $R$. papuanus were not known to Focke, so they have no place in any section.

2. Species with trifoliolate leaves, occurring in rather restricted areas: R. acuminatissimus (Sumatra, Java), R. copelandii (Philippines: Prov. Luzon), $R$. archboldianus, $R$. lorentzianus, $R$. macgregorii (New Guinea). Except for $R$. acuminatissimus, which was placed in section Rosaefolii, these species were unknown to Focke.

3. Species related to the latter group and belong to section Alpestres: $R$. alpestris. It has 5-foliolate palmate leaves and it was placed in this section by Focke (l.c.).

4. The remaining Malesian species: Rubus niveus with pinnate leaves and trifoliolate $R$. ellipticus share the feature of a dense, woolly felt underside of the leaflets, and have therefore been placed in section Ideanthi, but in different series. According to Zandee and Kalkman (1.c.) they are not very closely related each other.

In the light of macromorphological division, presented above, the pollen morphology and the relation between the species could be revised. On the basis of pollen morphology the following relation between the species of subgenus Idaeobatus is proposed and presented in Fig. 86.

\section{COMMENTS}

The macromorphological division proposed by Zandee and Kalkman (1981) does not always agree with the micromorphological one, based on the ornamentation pattern of the pollen.

1. As closely related species may be regarded New Guinean Rubus montis-wilhelmi and $R$. papuanus, species unknown to Focke (1.c., Zandee and Kalkman 1.c.), which have pinnate leaves. This is confirmed by a similar ornamentation pattern of the exine.

2. New Guinean Rubus ferdinandi-muelleri with pinnate leaves, from the section Pungentes presents a similar pattern of the pollen ornamentation and may be regarded as related with the two species mentioned above. On the basis 


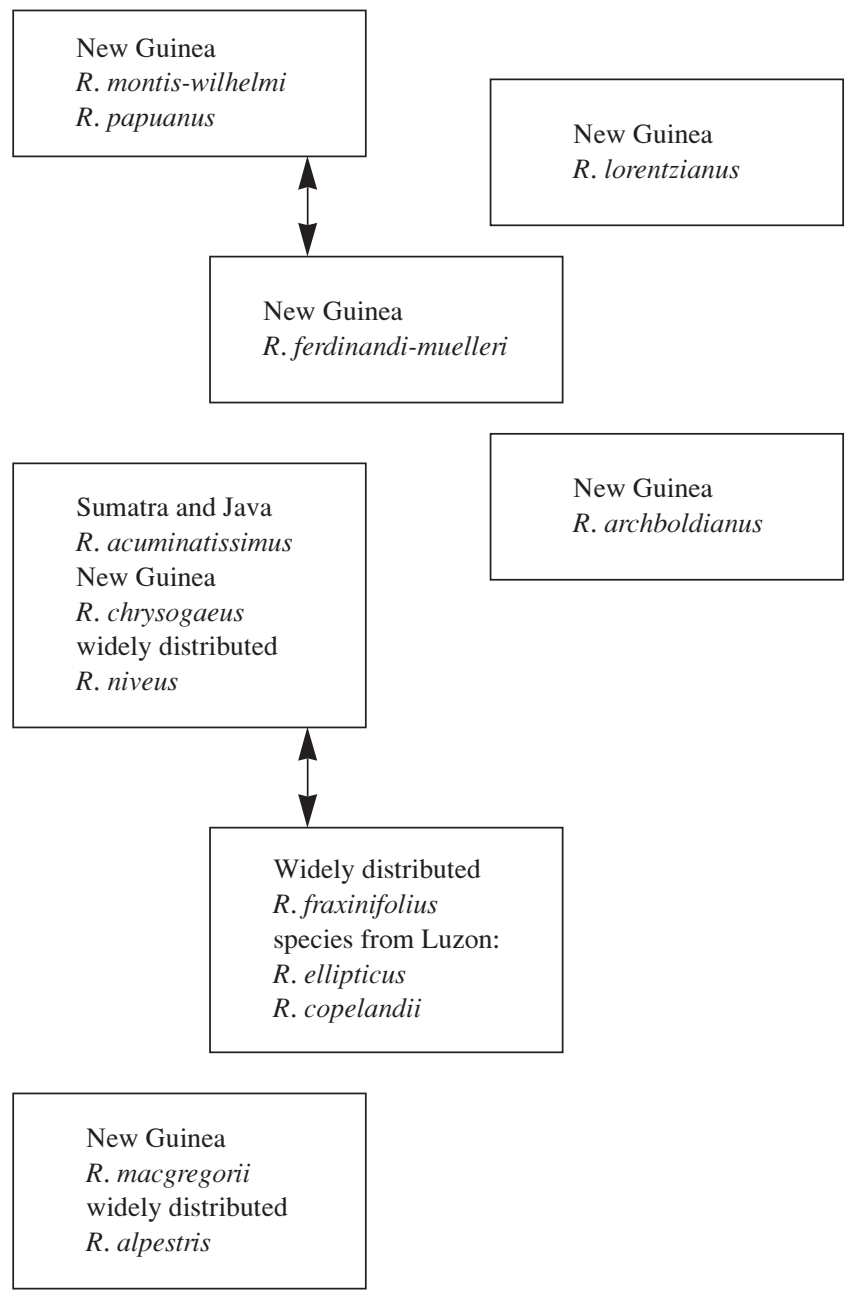

Fig. 86. Hypothetical relation of Rubus species of subgenus Idaeobatus, based on pollen morphology.

of macromorphology and pollen morphology the common systematical position of the three species: $R$. ferdinandimuelleri, $R$. montis-wilhelmi and $R$. papuanus in the section Pungentes has been proposed.

3. R. acuminatissimus, Rubus chrysogaeus, from section Rosaefolii, the former with pinnate leaves, whereas the latter with trifoliolate leaves, and $R$. niveus of section Ideanthi, have almost the same type of exine ornamentation and may be grouped together. This does not agree with the macromorphological division proposed by Zandee and Kalk$\operatorname{man}$ (1.c.).

4. Rubus ellipticus with trifoliolate leaves of section Ideanthi, trifoliolate $R$. copelandii, and $R$. fraxinifolius with pinnate leaves from section Rosaefolii have very similar ornamentation patterns. This demonstrates that apparently unrelated species may share similar pollen patterns.

5. Trifoliolate Rubus macgregorii from New Guinea and widely distributed $R$. alpestris have the same exine pattern; 5-foliolate palmate $R$. alpestris belongs to section Alpestre, whereas the systematic position of the former is unknown.

6. The trifoliolate Rubus archboldianus from New Guinea and trifoliolate $R$. lorentzianus could not be placed in any of mentioned groups because they have completely different patterns of ornamentation.

The studied samples were taken from the following herbarium specimens stored in the Nationaal Herbarium Ne- derland at Leiden. Photographs of the pollen grains presented in this article were taken from material indicated with an asterisk (*).

\section{SPECIMENS INVESTIGATED}

\section{- Rubus acuminatissimus}

Sumatra. West. Mt. Gombak, Pad. Bovenlands, Bünnemeijer 5630 (*); Mt. Ketambe, de Wilde c.s. 13713.

- Rubus alpestris

Sumatra. Aceh. Mt. Leuser, 2200 m, van Steenis 8532, $9123(*), 9706$.

- Rubus archboldianus

New Guinea. Papua New Chimbu Guinea, Western Highl. Distr. Chimbu, Millar \& Sayers NGF 23694; Gembol Subdistr. Mt. Wilhelm, LE 54832 (*).

- Rubus chrysogaeus

New Guinea. Papua New Guinea. Morobe Distr., Edie Creek, alt. 2430 m, Womersley NGF 24680, L 66389 (*).

- Rubus calycinus

Asia. Nepal. Tahshindu,. alt. 2400 m, van Steenis (1972) (*).

- Rubus copelandii

Philippines. Luzon. Mt. Pulog, alt. 2350-2450 m, Zandee 104901 (*).

- Rubus ellipticus

Thailand, Leo Kay Province, Tonkin Pres de Pakha Fang, alt. 1100 m, Poilane 17246 (*).

- Rubus ferdinandi-muelleri

New Guinea. Papua New Guinea. Western Highl. Distr., Wabag Subdistr. Merimanta, alt. $2430 \mathrm{~m}$, Hoogland \& Schodde 6739, 6920, Womersley NGF 9512 (*).

- Rubus fraxinifolius

Borneo. Sabah. Kinabalu Sabah National Park; Ranau Distr., alt. 1800 m, Badak SAN 32325 (*), Kadir A 1661, Poore H 141.

- Rubus lorentzianus

New Guinea. Papua New Guinea. Southern Highl. Distr. Tari Subdistr., Mt. Ambua, alt. 3250 m, Kalkman 4749, 4926, 4948, 4957 (*).

- Rubus macgregorii

New Guinea. Papua New Guinea. Central Distr., Mt. Victoria, Craven 2861, Croft LAE 61609, van Royen 10 798; Tapini Subdistr., alt. 3800 m, Zandee 4312 (*).

- Rubus montis-wilhelmi

New Guinea. Papua New Guinea. Western Highl. Distr., Kubor Range, alt. 3220 m, Vink 16118,16159 (*).

- Rubus niveus

Collected as Rubus leucocarpus from Ceylon

Ceylon. Central Province. Nuwara Eliya Distr., Kandapole, alt. 2000 m, Tirvengadun, Jaysuriya 1976 (*).

- Rubus papuanus

New Guinea. Papua New Guinea. Morobe Distr., Salawaket Range, alt. 3300 m, Hoogland 9934 (*). Western Highl. Distr., Mt. Kinkain, Vink 16116; Mt. Kegum, Vinas \& Veldkamp LAE 59786.

- Rubus pectinellus

Philippines. Luzon Mountain Province, Bontoc, Vanoverbergh 563; Mt. Polis, Britton PNH 1973; Mt. Pulog, Jacobs 7102, Steiner 2062; Mt. St. Thomas, van Steenis $18574(*)$. 


\section{AKNOWLEDGEMENTS}

I would like to thank the following persons who took part in preparing the plant material for these studies. Professor C. Kalkman $(\dagger)$ Leiden University, Holland, who determined brambles from Malesia; Bertie Joan van Heuven, under whose willing help I have prepared the pollen of Rubus for SEM and LM examinations; dr Raymond van der Ham, who kindly helped in acetolysis method and provided the suggestion in interpretation of the results, and Anna Dolatowska, who corrected the manuscript. These studies were supported by the State Committee for Scientific Research (KBN), grant no 6PO4C 10621.

\section{LITERATURE CITED}

CLARKE G.C.S., JONES M.R. 1978. The Northwest European Pollen Flora 17. Aceraceae. Rev. Paleobot. Palynol. 26: 181193.

EIDE F. 1981. Key to the Northwest Rosaceae Pollen. Grana 20: 101-118.

ERDTMAN G. 1952. Pollen morphology and plant taxonomy. Angiosperms. An introduction to palynology 1. Almqvist \& Wiksell. Stockholm.

FAEGRI K., IVERSEN J. 1964. Textbook of pollen analysis. Hather Press. New York. 1975.

FOCKE W.O. 1911. Species Ruborum. Monographie Genesis. Rubi Prodromus. Pars I, Stutgart.
FOCKE W.O. 1914. Species Ruborum. Monographie Genesis. Rubi Prodromus. Pars III, Stutgart.

HAM VAN DER R.W.J.M. 1990. Nepheliae Pollen (Sapindaceae). Form, Function and Evolution. Hortus Botanicus, Leiden.

HEATH G.L.A. 1984. The Northwest European Pollen Flora 34. Hippocastanaceae. Rev. Paleobot. Palynol. 42: 111-119.

HEBDA R.J., CHINAPPA C.C., SMITH B.M. 1987. Pollen morphology of Rosaceae of Western Canada. I. Dryas, Fragaria, Holodiscus. Can. J. Bot. 66: 595-368.

HEBDA R.J., CHINAPPA C.C., SMITH B.M. 1988. Pollen morphology of Rosaceae of Western Canada. II. Agrimonia to Crataegus. Grana 27: 95-113.

MOORE P.D., WEEB J.A., COLLINSON M.E. 1991. Pollen analysis. Blackwell Scientific Publications. Oxford.

PUNT W., REITSMA T., REUVERS A.A.M.L. 1974. The Northwest European Pollen Flora 2. Caprifoliaceae; Rev. Paleobot. Palynol. 17: 5-29.

REITSMA T. 1966. Pollen morphology of some European Rosaceae. Acta Bot. Neerl. 15: 290-307.

TOMLIK-WYREMBLEWSKA A. 1995. Pollen morphology of the genus Rubus L. I. Introductory studies of the European representatives of the subgenus Rubus L. Acta Soc. Bot. Pol.: 64, 2: 187-203.

TOMLIK-WYREMBLEWSKA A. 2000. Pollen morphology of the genus Rubus L. Part II. Introductory studies of the Malesian species of subgenus Micranthobatus. Acta Soc. Bot. Pol.: 69, 1: 31-40.

ZANDEE M., KALKMAN C. 1981. The genus Rubus (Rosaceae) in Malesia 1. Subgenera Chamaebatus and Idaeobatus. Blumea 27: 75-113. 